1

2

\title{
Has THE EURO-MEDITERRANEAN PARTNERSHIP AFFECTED MEDiterRANEAN BUSINESS CYCLES? *
}

\author{
Fabio Canova ${ }^{\dagger}$ and Alain Schlaepfer ${ }^{\ddagger}$
}

This draft May 25, 2012

\begin{abstract}
We date turning points of the reference cycle for 19 Mediterranean countries and analyze their structure and interdependences. Fluctuations are volatile and not highly correlated across countries; recessions are deep but asynchronous making average output losses in the area limited. Heterogeneities across countries and regions are substantial. Mediterranean cycles are time varying but their evolution is not linked with the Euro-Mediterranean partnership process. The concordance of cyclical fluctuations is poorly related to trade and financial linkages and to their evolution over time.
\end{abstract}

JEL classification: E32, C32.

Keywords: Turning points, Reference cycles, Euro-Mediterranean partnership, trade and financial interdependences.

*Canova acknowledges the financial support of the Spanish Ministry of Education grant ECO2009-08556 (Specification and Estimation of Models for Policy Analysis and Forecasting), of CREMED, and of the Barcelona Graduate School of Economics.

${ }^{\dagger}$ We would like to thank Jean Imbs for providing us with capital flows data. ICREA-UPF, CREI, CREMeD, CEPR; Department of Economics, UPF, Ramon Trias Fargas 25-27, 08005, Barcelona (Spain), fabio.canova@upf.edu

${ }^{\ddagger}$ CREI, Department of Economics, UPF, Ramon Trias Fargas 25-27, 08005, Barcelona (Spain), alain.schlaepfer@upf.edu 


\section{Introduction}

One of the main objectives of the Euro-Mediterranean partnership is to enhance economic and financial cooperation between member countries and create an area of shared prosperity through sustained socioeconomic development, see http://www.eeas.europa.eu/euromed. To achieve this goal, the EU has established preferential relationships with non-EU Mediterranean partners, including bilateral association agreements and the European neighbourhood policy (ENP). The scope of bilateral association agreements is to establish a regional free trade area, both in terms of North-South and of South-South relationships, and create a common regulatory platform among the partners. The ENP instead seeks to create an area of stability, prosperity, democracy and peaceful solution of conflicts by offering to participating countries a stake in the EU internal market, and supports economic convergence toward EU standards with important financial packages (the so-called ENPI instruments).

These association agreements produced structural reform in a number of Mediterranean countries - trade was liberalized, entry barriers for foreign banks into domestic financial markets were lowered, and red tape for starting business reduced - changing the structure of the local economies. For example, the EU is now the first trading partner of Mediterranean countries and Mediterranean partners (excluding Turkey) account for more than 5 percent of overall EU trade in goods. In addition, in the last 5 years Mediterranean exports (imports) to the EU increased by 11 (8) percent a year, the fastest growing percentage of any commercial area with the EU in the world. Similarly, Foreign Direct Investment (FDI) from the EU to the area, while still small in volume, have grown at the rate of 10 percent a year.

Drawing from similar experiences elsewhere in the world, one can conjecture that the increased interconnection with the EU will have positive effects on the growth prospects of the Mediterranean in the years to come. However, increased interdependencies are likely to bring an important side effect: economies which in the past were insulated from EU cyclical fluctuations are now likely to be more affected by them. Thus, from a theoretical point of view, it is important to measure the impact of the Euro-Mediterranean partnership on Mediterranean business cycles and, from a welfare point of view, to consider the externalities that EU policies may have for business cycles non-EU countries in the region.

How should one expect cyclical fluctuations of a small economy to change when it becomes more interconnected with a large economy? Increased cross-border interdependences should 
make cyclical fluctuations more similar. Greater openness to trade and increased financial flows are likely to make the small economy more sensitive to external shocks and increase the comovements of domestic and foreign variables by expanding or intensifying the channels through which shocks spill across countries. However, increased economic integration could lead to more asynchronous output fluctuations, as countries specialize in the production of goods for which they have comparative advantage and freely trade them in the world markets. Thus, production cycles could become idiosyncratic while consumption cycles are perfectly correlated. While there is evidence in favour of the first type of effects (see e.g. Canova and Dellas, 1993, Frankel and Rose, 1998), many Mediterranean countries possess natural resources absent in the EU, thus making the second hypothesis relevant for the region. In general, to evaluate the effects that the Euro-Mediterranean partnership will have on the cyclical fluctuations and the welfare prospects of the area, one must know how cyclical fluctuations in the Mediterranean basin look like and understand what contributes to transmit fluctuations within the region and from the EU to non-EU countries. Canova and Ciccarelli (2012) provide a first look at business cycles in the area and at their time variations but do not study the structure of cyclical fluctuations nor the transmission mechanism across countries. This paper fills this gap and contributes to the literature in two ways.

For students of business cycles, we provide a novel business cycle turning point classification, which was unavailable for many countries in the region and absent for the Mediterranean as a whole, and a set of stylized facts summarizing the features of fluctuations in the area. Both are likely to useful to test domestic and international models of the business cycle, to understand the cyclical characteristics of developed, developing and frontier economies, and to evaluate in which direction existing models need to be modified to capture realistic aspects of Mediterranean fluctuations. For policymakers, we provide a characterization of the cyclical fluctuations in different countries and regions of the basin, which may help them to formulate policies better achieving their integration goals, and an interim evaluation of the effects of the Euro-Mediterranean partnership. Finally, because policy actions are primarily directed to increase trade and financial interdependences in the region, and because a large literature tries to explain the increased correlation of cyclical fluctuations between developed and less developed countries via trade and financial links (see e.g. Imbs, 2010, for a recent effort and references within), we measure what variations in trade and financial interdependencies have done to cyclical fluctuations in the area. 
We use up to five quarterly series (real GDP, unemployment, industrial production, real income, and real sales) for 19 Mediterranean countries in our exercise. Since not all the series are available and for the entire time span, and since starting dates are often irregularly distributed, we use different weighting schemes to aggregate variables specific turning points and choose turning point dates to minimize distortions and spurious patterns.

Mediterranean business cycles have some standard features but also important specificities, which set them apart from those of other regions of the world. In particular, a vast heterogeneity of patterns in terms of persistence, volatility and comovements emerges across countries and regions. We find, for example, that cyclical upturns and downturns are not generally well synchronized, and while comovements increased in the recent recession, its absolute level is considerably below the one reported for countries in Asia or Latin America. The number complete cycles in different countries (regions) is also different and amplitudes and durations are very much country specific. Finally, the cross sectional distribution of output losses in recessions is quite spread out and North African countries are decoupled from the major EU countries in the region in this respect.

The structure of cyclical fluctuations changes over time. However, while persistence and the volatility are affected, the concordance of turning points is not. Thus, it is difficult to associate these variations with the political and institutional changes that the EuroMediterranean partnership has brought about. Finally, while the correlation between bilateral interdependences and the synchronicity of cyclical fluctuations has increased over time on average, it does not appear to be generally true that Mediterranean countries who signed trade agreements with EU saw this correlation increase more than the average. Hence, either the effects of the Euro-Mediterranean partnership have not yet materialized, because of institutional and political delays, or the heterogeneity of Mediterranean economies is so large that current measures, while going in the correct direction, only have minimal impact on the correlation structure of cyclical fluctuations. The recent political turmoil in the Arab world suggests that both stories could to be true and that more needs to be done before the Mediterranean becomes a meaningful economic entity.

The rest of the paper is organized as follows. The next section describes the methodology used to date turning points of individual series and to aggregate individual turning points into a reference cycle, and the statistics used to summarize the characteristics of reference cycles. Section 3 presents the main results. Section 4 concludes. 


\section{The methodology}

The literature concerned with the detection of turning points in economic activity has generally followed two approaches (see Hamilton, 2010, for a survey). The dominant approach, both in academics and in the real-time practice of dating committees, focuses attention on few aggregated time series and date turning points employing particular macroeconomic aggregates. For example, a turning in economic activity is typically calculated using real GDP or an index of coincident indicators. Press releases of the NBER and the CEPR Business Cycle Dating Committees indicate that a handful of aggregated macroeconomic time series are typically looked at but that certain variables (such as employment and GDP) receive a larger weight in the decision to call a turning point or not (see e.g. NBER, 2008, or CEPR, 2010). The existing practice is therefore consistent with the idea that one should try to aggregate macroeconomic information first and then detect turning points using highly aggregated series (we call this the " average then date" approach).

As Harding and Pagan (2002) and (2006) have suggested, the "average then date" approach is inconsistent with the methodology employed by pioneers of business cycle analysis, who instead considered a large number of disaggregated series, identified turning points in each of these series, and then determined reference cycle turning points using the distribution of the turning points of the disaggregated series; see Burns and Mitchell (1946, p. 13 and pp. 77-80) (we call this the "date then average" approach).

The two methods are likely to give different turning points classification and a different picture of various cyclical phases since the aggregation of non-linear functions (such as dating turning points) is not the same as the non-linear function of the aggregate. Nevertheless, there are theoretical and practical reasons to consider both methods useful. In general, little is known about the properties of the two approaches and apart a few motivated cases (see e.g. Stock and Watson, 2010), it is a matter of taste which procedure is selected.

In this study, we use the "date then average " approach and construct reference cycles for a country, a region, or an area. Our effort is constrained by strong data limitations. Data availability in fact forces us to concentrate attention on up to five quarterly real indicators (GDP, industrial production, unemployment rate, real income and sales) and for 19 Mediterranean countries only - Algeria, Croatia, Cyprus, Egypt, France, Greece, Israel, Italy, Jordan, Lebanon, Malta, Macedonia, Morocco, Portugal, Serbia, Slovenia, Spain, Tunisia and Turkey 
1. The series are chosen to maintain the closest match with the practices of the NBER and the CEPR dating committees. Because not all series are available for all countries and, in a country, the starting date of different series often differ, time varying weights are used to construct the reference cycle in individual countries. The weights are restricted so that at each point in time they sum to one. Thus, our approach can be thought as the discrete time counterpart of the weighting scheme for stratified data of Stock and Watson (2010).

We date turning points in the (log) level of individual series. Hence, the cycles we examine are "level" rather than "growth" cycles - the latter are computed after a trend is removed from each time series. Level cycles are preferable because it is difficult to specify the time series properties of the trend and its correlation with the cycle in small samples (see e.g. Canova, 2007). These difficulties lead to important specification and measurement errors that may distort our perception of the features of cyclical fluctuations

\subsection{Dating turning points in individual series}

To date turning points in individual series we adapt Bry and Boschan's (1971) methodology to quarterly data. Since the approach is relatively well known in the literature, we only briefly describe its features.

An observation $y_{t}$ is considered a candidate peak of a variable $y$ if $y_{t} \in \max \left\{y_{t-2}, y_{t-1}, y_{t}, y_{t+1}, y_{t+2}\right\}$, and a candidate trough if $y_{t} \in \min \left\{y_{t-2}, y_{t-1}, y_{t}, y_{t+1}, y_{t+2}\right\}$. This rule is weaker than a rule that imposes, for example, that a candidate peak satisfies $y_{t-2}<y_{t-1}<y_{t}>y_{t+1}>y_{t+2}$ and a candidate through satisfies $y_{t-2}>y_{t-1}>y_{t}<y_{t+1}<y_{t+2}$. Therefore, we impose additional restrictions to reduce the set of potential turning point candidates. A candidate is accepted as a actual turning point if the following censoring rules are satisfied:

- Peaks and troughs must alternate. In case of a violation, e.g. a peak is followed by a peak, the lower of the two peaks is eliminated.

- A peak (though) must be higher than the previous trough (peak).

- The minimum length of a peak-peak and a trough-trough cycle is 5 quarters.

- The minimum length of a peak-trough and a trough-peak phase is 2 quarters.

\footnotetext{
${ }^{1}$ When constructing a reference cycle, we date $-u_{t}$, so that a peak corresponds to a low level of unemployment and a through to a high level of unemployment.
} 
- Turning points occurring in the first 2 and in the last 2 quarters are eliminated.

- Peaks (troughs) at the beginning or end which are lower (higher) than the initial (ending) values are eliminated.

The first two restrictions are obvious and require no comments. The third and the fourth are arbitrary but typical in the literature. For robustness, we have also produced a turning point classification requiring that a complete cycle must last, at least, 7 quarters and that expansion and recession phases must last, at least, 3 quarters (see appendix B). The last two constraints are employed to avoid that measurement errors and data revisions spuriously affect turning point dates. These rules were sufficient to uniquely date turning points in all the series and in all countries.

\subsection{Constructing a reference cycle for each country}

Consider a series $y_{i t}^{j}, i=1, \ldots, 5$ in country $j=1, \ldots, 19$. Given the turning points dates we have computed for each individual series, we calculate at each $t$ the distance in quarters to the nearest peak and create the new series $m p_{t}(i)^{j}$. Similarly, we calculate at each $t$ the distance in quarters to the nearest trough and create the new series $m t_{t}(i)^{j}$. We then aggregate $m p_{t}(i)^{j}$ and $m t_{t}(i)^{j}$ over $i$ and look for dates where the two aggregates reach their minimum. Intuitively, low values in $m p_{t}^{j}\left(m t_{t}^{j}\right)$ indicate that several series are close to a peak (through) at time t. Thus, local minima of $m p_{t}^{j}$ and $m t_{t}^{j}$ are candidate peaks and troughs of the reference cycle. Once the candidates are identified, the same censoring rules used to date individual series turning points are applied to candidate reference turning points, and a unique set dates is selected for each country.

How one aggregates the individual $m p_{t}(i)^{j}$ and $m t_{t}(i)^{j}$ matters, especially because not all series start at the same date in each country. We have experimented with a number of approaches, including employing the simple mean, the weighted mean (with higher weights given to output and unemployment), and the median as an aggregate measure. In what follows, we primarily discuss results obtained when the weighted mean is used to aggregate single series information. .For comparison, we also report country specific reference cycles dates obtained when the median is used to aggregate single series information. 


\subsection{Constructing a reference cycle for a region}

With reference cycle for each country $j=1, \ldots 19$, we apply the same techniques described in the previous subsections to construct a reference cycle for a region or an area. That is, for each $j$, we construct two new series $r p_{t}^{j}$ and $r t_{t}^{j}$, measuring the distance in quarters to the nearest peak and the nearest trough. The two series are then aggregated over $j$ belonging to a region or an area and we search for minima in the two aggregated series. Once candidate dates are identified, we apply the same censoring rules used for individual series and countries to identify a regional or an area reference cycle turning point.

We considered various regional grouping. Since there is some evidence that cycles tend to cluster around certain geographical poles (see Canova and Ciccarelli, 2012), we split the Mediterranean into four geographical regions - Major European countries (Portugal, Spain, France, Italy, Greece), other European countries (Malta, Cyprus, Croatia, Macedonia, Serbia and Slovenia), East Mediterranean countries (Turkey, Lebanon, Jordan and Israel) and the North African countries (Egypt, Algeria, Tunisia and Morocco). We also aggregate country specific information using the monetary arrangement - in a group we have Euro-area countries and in the other non Euro-area countries - or the level of income-per-capita at the end of the sample - in one group we have the poor countries and in the other the rich countries.

The Mediterranean reference cycle is obtained aggregating the reference cycles of the 19 countries using the same censoring rules previously described.

\subsection{The features of cyclical fluctuations}

We summarize the features of the reference cycles with four statistics: the duration of expansions and recessions; the amplitude of expansions; the magnitude of the cumulative movements in recessions and the bilateral concordance of business cycle turning points.

The duration statistics measure the persistence and the amplitude statistics the volatility of cyclical fluctuations. Taken together they may suggest the presence of asymmetries in business cycle phases which, in turn, inform us about potentially non-linearities in the process generating cyclical fluctuations. We compute amplitudes and cumulative movements in recession using both real GDP and industrial production. While industrial production is a more imprecise proxy of the level of aggregate level economic activity, especially in countries where the service sector is large, it has the advantage of being available for all countries - 
GDP in many cases it is not. Amplitude measures are reported in percentage terms, relative to the previous turning point; that is, we report the level of GDP (IP) at the peak relative to the level of GDP (IP) at the though minus one. This facilitates the quantification of size of the fluctuations. We compute the magnitude of cumulative movements in two ways: using the actual decrease in GDP (IP) or using its triangular approximation. Letting $D_{i}$ be the duration of phase $i$ and $C_{i}$ the amplitude of phase $i$, the triangular approximation to the cumulative movements in phase $i$ is $C_{i}=0.5\left(D_{i} C_{i}\right)$. This statistic gives us an idea of the output loss incurred, say, in a recession - a measure which is typically of interest among policymakers and approximates the welfare losses of business cycles that can be computed in theoretical models. Finally, the concordance index is a pairwise measure of the synchronization of the reference cycle turning points.

Since we are interested in assessing whether countries which have entered in preferential agreements with the EU present important differences in their cyclical statistics relative to countries which have either not entered in such agreements, we will compare amplitude, duration and concordance measures over subsamples.

\section{The results}

The presentation of the results is organized in four parts. First, we describe the features of the reference cycles of individual countries, of selected regions, and of the Mediterranean. Second, we discuss summary statistics characterizing these reference cycles. Third, we study how summary statistics change over time. Finally, we examine the importance of trade and financial interdependencies for cyclical fluctuations in the area and zoom-in on the relationship for a selected countries that have entered preferential agreements with the EU.

\subsection{The turning points of the national reference cycles}

Table 1 presents the chronology of turning points for each of the 19 countries. As far as we know, it is the first time that such a compilation is presented for Mediterranean countries. This information is useful for researchers analyzing cyclical fluctuations in developed and developing countries and for policymakers interested in devising measures increasing their synchronization. A chronology of the turning points for the individual series in each country appears in appendix B, both when a five-quarters and a seven-quarters minimum duration 
rule are employed to classify complete cycles.

In general, how we aggregate individual series turning points into a reference cycle does not matter much - compare the two columns of table 1 - and even less so when only some of the five aggregate macroeconomic series are available. Since for less developed countries of the area, sales, real income and GDP are not often available, the dates we obtain for these countries are quite robust. Classification differences appear for the main European countries and primarily occur when not all of the five variables are in phase. For example, there is a complete cycle in France between 1973:4 and 1974:4 when the reference is cycle is constructed using the weighted mean, which is absent when the median is employed. Similarly, the complete 1998:2-1999:4 cycle, which appears when the median is used to aggregate individual French series turning points, is absent when the weighted mean is employed. Overall, complete cycles tend to be slightly longer and less numerous when the median employed. Therefore, it is more difficult to pass the censoring rules for turning point classification when the median is used to aggregate individual information. However, when a turning point is found, it is more difficult to exit a cyclical phase if the median is used.

Reference cycles have quite heterogeneous features. They appear to be relatively short in some countries, see e.g. Greece, Italy and Portugal, but in others, long expansions phases are present, see for example, Cyprus from 1995:3 to 2008:3; France from 1958:3 to 1974:3 and from 1993:3 to 2008:1, Jordan from 1995:3 to 2009:3, Slovenia from 1999:1 to 2008:3, and Spain from 1982:3 to 1991:4 and from 1993:2 to 2007:3. Recessionary phases are, on average, shorter than expansionary phases, but not uniformly so (see, for example, the case of Italy). Interestingly, the features of reference cycles of developed, less developed and frontier economies in the area are not very different. In fact, in each of these groups, there are countries which display cycles with short or long periodicity and these could be symmetric or asymmetric. Thus, reference cycles do not cluster along a development indicator. Similarly, being or not being a member of the EU is irrelevant for the structure of cyclical fluctuations: the only difference being that turning points are slightly more frequent in the non-EU members. A more detailed investigation of the effects of institutional and geographical factors on Mediterranean cyclical fluctuations is in the next subsection.

The most recent recessionary episode gives a useful snapshot of how heterogeneous reference cycles are nowadays and an independent check on the reasonableness of the procedure used to construct reference cycles. The Mediterranean seems to be split into three different 
portions: the first portion includes countries which experienced a recession and by 2010 are back into an expansionary phase; the second comprises countries which entered a recession and have not yet displayed a cyclical through; and the third includes countries missing the recession and displaying only an irregular and temporary slowdown in economic activity. In the first group we have Croatia, Egypt, France, Italy, Lebanon, Malta, Morocco, Portugal, Slovenia, Tunisia and Turkey; in the second group we have Cyprus, Greece, Israel, Jordan, Macedonia, Serbia and Spain; Algeria is the only country without a recession. Note however that there is considerable variation in the turning point dates in the first two groups: peak dates are scattered over the 2007:3-2009:3 period but 2008:2 and 2008:3 have the highest frequency; through dates instead are almost uniformly distributed between the 2008:2 and 2009:2. Therefore, while there appears to be a certain degree of synchronization in entering the recession, there is a high degree of non-synchronization in exiting it. This observation is consistent with what is known in the literature. For example, Canova et al. (2007) suggested that G-7 cycles are more synchronized in recessions than in expansions and Imbs (2010) termed the 2008-09 recession "the first global recession in decades", because of the synchronicity in the timing and the generality of the pattern.

The presence of heterogeneities in the 2008-09 recessions is highlighted in Figure 1, which presents the dynamics of output and of the unemployment rate since each country's last cyclical peak. For comparison, the cyclical peak is normalized to 100 and scaled so that it occurs in period 1 in each country. Clearly, the dynamics entering (and exiting) the recession are quite different across countries. We have countries mild and relatively short output recessions (France, Morocco, Italy, Portugal and Tunisia), countries with sharp and short output recessions (Lebanon) and countries with relatively long and mild recessions (all the others, including those which have not experiences a cyclical through). Some countries display a sustained trend increase in unemployment since the last cyclical peak (e.g. France, Italy and Spain), in others the unemployment rate is quite acyclical (e.g. Egypt, Morocco and Tunisia) and in one the unemployment rate falls during the recession (Croatia). Note that the unemployment rate lags the reference cycle in major European countries by one or two quarters, but elsewhere real activity and the unemployment rate are quite coincident. Hence, even during this "global" recession, cross country difference in the size of output and unemployment losses, in the duration and the persistence of the episode are quite large. 


\subsection{A chronology for regions and for the Mediterranean basin}

Given the large number of countries we examine and the considerable idiosyncratic component present in the national cyclical fluctuations, it is difficult to construct stylized business cycle facts for the Mediterranean using national reference cycles. For this reason, we collapse the individual country information into regions constructed using geographical characteristics, monetary arrangements, and the wealth per-capita at the end of the sample. When we use geographical characteristics, we split the countries into four groups. In the Major European countries group we have France, Italy, Spain, Portugal, Greece; in the Other European countries group we have Croatia, Slovenia, Serbia, Macedonia, Malta, Cyprus; in the Eastern Mediterranean group we have Turkey, Israel, Lebanon, Jordan; and in the North Africa group we have Morocco, Tunisia, Egypt, Algeria. When we split countries according to their institutional arrangements, we put countries which belong to the Euro area (France, Italy, Spain, Portugal, Greece, Slovenia, Malta, Cyprus) in one group and the rest in the non-Euro area group. Finally, when we reorganize business cycle information using a wealth indicator, we choose 29.000US dollars for GDP per capita (PPP adjusted) in 2010 as cut off point. Thus, France, Italy, Spain, Israel are the rich countries, while the poor group includes all the others. Table 2 reports turning points dates clustering the 19 countries into these alternative regional groups.

When geographical proximity is used to group countries, regional heterogeneities are still overwhelming. For the common samples, turning points are hardly synchronized and certain regions experience many more (short) cycles than others. For example, consistent with the CEPR classification, the Major European countries group displays only 3 complete reference cycles with recessions starting in 1980:1, 1992:1 and 2008:1. On the contrary, the Other European countries group displays 5 full complete reference cycles over the last 30 years; and the North African countries group has 5 complete reference cycles but now for the shorter sample starting in 1990:1. Thus, not only the concordance of regional cycles is low; the persistence of regional cycles is also quite different.

The most recent recession in the Major European countries lasted roughly one year, twice as long as in the Other European countries group or in the North Africa group. For the Eastern Mediterranean group a trough can not yet be identified, because the four countries in the region are quite heterogeneous in both the timing of the upturn and the magnitude of the fall, making the recession appear quite long. For example, while Turkey roughly 
follows the pattern of the Major European countries group, Israel and Jordan have not yet displayed a through and in Lebanon a recession started about one year earlier than in the other countries and terminated by 2008:2.

The other two classifications confirm the presence of profound differences in the nature of cyclical fluctuations in the Mediterranean. The Euro area group displays seven complete cycles, most of which are concentrated in the early part of the sample, with expansions being generally longer than contractions while the non-Euro group displays six complete cycles, but its time distribution is exactly the opposite of those in the Euro group (four cycles occurred in the last 15 years), and cycles are more symmetric. Moreover, at least at the beginning of the sample, expansions phases for the non-Euro group of countries are quite long, suggesting a growth convergence pattern. On the other hand, complete cycles are more numerous in the rich region; the frequency of complete cycles is larger in the earlier part of the sample in the rich region and more equally divided for the poor region; recessions are generally shorter than expansions in the rich region while recessions are quite long in the poor region.

Despite the heterogeneous nature of cyclical fluctuations in the region, the Mediterranean reference cycle for the we construct is the first of its kind for the area and it is relevant for both students of business cycles and for policymakers. For example, it can be used to compare business cycles in the region with those of continental Europe and help us to understand whether the region is getting more integrated into the world business cycle or not. Before we describe its features, it is useful to remember that over the available sample, the number of series employed to construct the reference indicator varied with time. In particular, at beginning of the sample only data from the Major European and from some of the Eastern Mediterranean countries is available; for the last decade, data for all countries is more or less available. Hence, the Mediterranean reference cycle reflected the cyclical development of Europe more than those of the Middle East or Africa at the beginning of the sample; but it is more balanced in its regional coverage at the end of the sample.

The Mediterranean displayed 7 complete cycles over the last fifty years. The length of the cycles is quite irregular, varying from a minimum of just above 2 years to a maximum of 13 years and with mean value of 6.7 years, and the persistence of business cycle phases varied considerably over time. For example, the 1970s were a particularly turbulent period and three recessions materialized in the eight years from 1974 to 1982; the remaining decades have been more stable and one complete cycle, featuring long expansions and relatively 
short recessions, took place in each. Interestingly, while the US and part of Europe were booming between 1997 and 2001, the region experienced a long recessionary phase during this period. Rather than being due to contagion effects of crises taking place elsewhere in the world, the main reason for this long recession is that the majority of the countries displayed unsynchronized throughs and very slow and uncertain recoveries.

Figure 2 zooms in on the last recession and shows the dynamics of real activity and of unemployment around the Mediterranean peak (which occurred in 2008:2). Once again the level of each series in each country is normalized to 100 at the cyclical peak. Consistent with the expectation, real activity displays an inverted U-shaped pattern even though, in some countries, this occurs with a lag relative to Mediterranean peak. There are also several outliers to the pattern and, for example, during the recessionary phase (which lasted until 2009:2) Cyprus, Lebanon, Algeria and Morocco quickly surpass the activity level achieved at the Mediterranean peak. The unemployment rate has a the typical U-shaped pattern in many countries. Significant outliers here are Italy, Spain, Turkey and Croatia: in the first three countries, the unemployment rate start increasing up to six quarters prior to the Mediterranean peak: in Croatia, it is falling before and after the peak.

\subsection{Durations, Amplitudes and Concordances}

We summarize the cyclical information present in the reference cycles we have constructed in table 3. We report the average duration in quarters of each phase and the average amplitude of expansions computed using GDP growth or, when unavailable, using IP growth. Table 4 reports the average cumulative fall in GDP growth (or IP growth) in recessions.

Cyclical fluctuations are generally asymmetric: the average duration of expansions exceeds, and sometimes considerably, the average duration of recessions. The Mediterranean spends about 75 per cent of the time in expansions, while the proportion varies between 62 and 90 percent when we consider a geographical classification, between 55 and 84 percent when we use the monetary classification, and between 76 and 78 percent when we use a wealth classification. Expansions last, on average, from 3 years to almost 8 years depending on the grouping; recessions last, on average, from one to over 4 years depending on the grouping. The largest asymmetries in the duration of business cycle phases occur in major European countries; in the Eastern Mediterranean and non-European countries asymmetries are moderate. Interestingly, the duration of cyclical phases is very marginally related to the 
wealth of a country, while geography and the monetary regime matter quite a lot.

The volatility of cyclical fluctuations is significant. The average percentage change in either GDP or IP growth for the Mediterranean is around 35-40 percent. Thus, the peak is, on average, more than one third higher than the through. However, there are important regional differences. For example, in other European countries, GDP at the peak is over 70 percent higher than at the trough, while in the North African region the peak is only 10 percent higher. Similarly, in Euro area countries the peak is, on average, higher than the through by about 60 percent while for non-Euro countries the peak is only 10 percent above the trough. Finally, as in the case of duration, the wealth classification seems to be irrelevant for clustering amplitudes: both rich and poor countries have peaks that are about 35-40 percent higher than troughs.

There is a positive but moderate association between cyclical phases across countries: the mean of the concordance index is 0.62 (the mode is 0.65 ), the cross sectional distribution of the index is approximately normal, ranges from 0.3 to about 0.9 , and the standard deviation is 0.10. The concordance of cyclical phases is higher among Major European countries and lower among the rest of the countries or between these and the Major European countries. The concordance of turning points for other regional classifications is quite dispersed and although the mean is slightly higher (about 0.70), the distribution is far from normal.

The cumulative loss in recession for the average Mediterranean country is small and generally becomes larger when industrial production growth is used. The loss for the Major European countries is also small, while losses for Euro area countries are marginally larger. The average losses for the remaining classifications are positive. To understand this somewhat surprising outcome it is important to remember that recession dates are chosen using the reference cycle for the region (or the area) while losses are calculated averaging the movements in domestic GDP (or IP) growth over those dates. Thus, if there is a large heterogeneity in the timing of the recessions for the countries in the group or if real activity in some countries is strongly asynchronous with the reference cycle, positive and possibly large numbers could result. Hence, the entries of table 4 suggest that GDP (IP) growth fluctuations in countries located in the Eastern part of the Mediterranean and do not adopt the Euro not only have low synchronization with the reference cycle we construct, but often show countercyclical movements.

To summarize, cycles phases are generally asymmetric in the Mediterranean, with expan- 
sions lasting, on average, longer than recessions; fluctuations are not very highly correlated and this is true even for countries sharing a border or having similar structural characteristics; recessions can be deep but average output losses in the area are limited due to the lack of synchronization of output growth turning points. Perhaps the most remarkable feature which distinguish the Mediterranean from other regions in the world is the considerable heterogeneity in the structure of business cycle fluctuations. Cyclical upturns and downturns are generally not highly synchronized across countries or within regions, and while synchronization increases in the most recent recessionary episode, its absolute level is far below the one reported in other regions. Amplitude, durations and concordances measures all have regional and country specific characteristics. Finally, the cross country distribution of output losses in recessions is quite spread out and losses in North African countries are different from those experienced, e.g., by the major European countries of the area.

While the snapshot is not very encouraging as far as regional integration and shared prosperity are concerned, one should also recognize that time averaged statistics may mask important convergence tendencies. After all, it is only since 1995 that policy measures have been taken to foster integration in the area and to share the prosperity that this integration will produce. For this reason, the next subsection examines the evolution of amplitude, duration and concordance measures over two sample periods.

\subsection{Are there time variations in the cyclical fluctuations?}

While for many countries the sample is not very long, a subsample analysis is useful from at least two perspectives. First, we would like to know whether the globalization trends, which have led to a much higher synchronicity in the cyclical fluctuations between developed and developing countries, are shared by the countries of the Mediterranean basin. Second, since political and economic ties have been enhanced, we want to know whether this process has also brought about changes in the cross country nature of cyclical fluctuations. We split the sample at two different dates: at 1995, when the Barcelona process started, and at 2000. This latter date does not have any special economic interest and it is selected to allow for delays in the effects of the partnership agreements.

Table 5, which reports how durations and amplitudes have varied when countries are grouped according to the same regional classifications previously used, suggests that duration statistics are changing, but both the magnitude and the direction of the change is phase and 
region specific. For example, when the Mediterranean reference cycle is used, recessions last 7.2 quarters in the first period and 9.5 quarters in the second, irrespective of the cut-off date, while booms last roughly 20 quarters in the earlier period and 21.5- 26 quarters in the later period, depending on the cut-off date. The length of booms increases in the second sample in all European countries while it decreases in the Eastern Mediterranean and in North Africa. Conversely, the length of recessions is roughly unchanged in the major European countries, it decreases in the other European countries and in the Eastern Mediterranean, and it increases in North Africa. A similar heterogeneity appears with the other two regional classifications. In Euro area countries cyclical phases have become more asymmetric (the length of booms increases and the length of recessions decreases on average), while in non-Euro area both phases become less persistent (both the length of booms and recessions decreases on average). In rich countries, asymmetries are exacerbated in the latter part of the sample, while they are smoothed out in poor countries, primarily because expansions become less persistent.

Time heterogeneities are also evident in amplitude measures. For the Mediterranean as a whole, expansions become longer in the second sample when we use 1995 as cut-off date while the opposite is true when using 2000 as cut-off date. We also find that in European countries expansion phases have become stronger while in the Middle East and North Africa expansions have become weaker. In Euro area countries the amplitude of expansions is larger (smaller) when we use the 1995 (2000) cut-off point while for non-Euro area countries no major change is visible. Finally, the amplitude of expansions increases both in rich and poor countries, regardless of the cut-off point used.

Interestingly, there are minor changes in the distribution of the concordance index across subsamples. The mean value of the index is 0.62 for the whole sample, 0.60 for the sample up to 2000, and 0.64 for the sample starting at 2001. Thus, while the mean value of the concordance index increases, the increase is not as large as the one reported in, e.g., Imbs (2010), who looked at a large cross section of developed and developing countries.

In conclusion, the features of cyclical fluctuations are changing over time with duration and amplitude measures being more affected than the concordance index. However, depending on the regional classification used, cyclical asymmetries turns out to be exacerbated or smoothed out, persistence increased or decreased, and volatility reduced or boosted. Hence, not only cyclical fluctuations in the Mediterranean are heterogeneous; their time evolution is also heterogeneous and there is little evidence that a convergence process is taking place. 
In this sense, the Mediterranean stands quite apart from the globalization trends observed elsewhere in the world. Furthermore, the time variations we detect are hard to link directly or indirectly to the Euro-Mediterranean process and the political changes that have followed.

\subsection{What is the role of trade and financial links?}

To learn more about the nature of cyclical fluctuations in the Mediterranean, we next examine how the distribution of the bilateral concordance index relates to the distribution of bilateral trade and financial linkages. We construct bilateral trade (financial) measures summing up imports and exports (capital inflows and outflows) of two particular countries and dividing the result by the sum of total exports and imports (capital inflows and outflows) of the two countries and averaging the result over time. We compute both simple and rank correlation statistics. Since the results are similar, we focus the discussion on rank correlations only.

The correlation between concordance and trade indices is quite low - for the full sample it is only 0.22 . Thus, countries with a high concordance in the timing of cyclical fluctuations are not necessarily those with high bilateral trade relationships. When we split the sample at the end of 2000, the rank correlation is practically unchanged across subsamples ( 0.20 in the first sample, 0.19 in the second), while there is a slight increase when simple correlations are used (from 0.17 to 0.25 ). Overall, the relationship remains quite weak in the 2000s.

To look at the same issue from a different angle we compute the percentage of the cross sectional dispersion of the concordance index explained by the cross section dispersion of bilateral trade measures. Trade dispersion explains just 7 percent of the dispersion in the concordance index and for the subsamples the percentage is even lower (1.5 percent in the first, 6 percent in the second). Thus, trade seems to be only a minor determinant of the synchronicity of cyclical fluctuations in the Mediterranean and the recent increase in trade flows has not brought about larger cyclical synchronization.

Why is it that trade does not matter? One possibility could be that bilateral trade relationships do capture the extent of trade interdependencies in the region because third countries, outside of the Mediterranean, act as assemblers and exporters of domestically produced products. While this could be an explanation, it is hard to identify who these third countries could be. Alternatively, the generally low correlation between business cycle synchronization and trade could be due to the fact that bilateral trade in the Mediterranean is limited and that for many countries, the main trade partner is the EU. Thus, the results 
may be spurious since many leakages we considered are not operative. To check for this possibility we focus attention on the concordance of cyclical fluctuations of Morocco and Tunisia, who signed trade agreements with the EU in the middle of the 1990s, with Major European countries and examine the evolution of the trade-concordance correlation over time. We want to see whether the concordance index is better correlated with bilateral trade for this restricted group of countries and whether signing a trade agreement with the EU has changed not only the extent of bilateral trade but also the synchronicity of cyclical fluctuations. It turns out that for the full sample the rank correlation between the two indices is 0.35 , higher than what we obtained for all possible pairs in the Mediterranean. However, the percentage of the cross sectional dispersion of concordances explained by the dispersion of trade indices is low (4 percent) and trade explain less of the concordance of cyclical fluctuations in the 2000s than in the earlier part of the sample (0.12 vs. 0.34).

Hence, not only the synchronicity of the cyclical fluctuations does not have much to do with trade; there is also little evidence that changes in trade relationships are associated with variations in concordance of cyclical fluctuations either in absolute terms or relative to the average variations in the area. Since trade does not seem to matter, what else could explain the dispersion of concordances in the Mediterranean? A few suspects comes to mind. The first is financial interdependencies. Financial and banking interdependences are quite low in the area but have increased over the last 10 years. To examine their importance, we have correlated concordance measures with bilateral capital movements for Cyprus, France, Greece, Italy, Jordan, Portugal, Spain, Tunisia and Turkey, which are the only countries for which flows are available. The rank correlation is similar to the one obtained with bilateral trade (0.23) and the percentage of the dispersion of the concordance index explained is equally small (11 percent). The rank correlation slightly increases if the concordance distribution obtained after 2001 is used (0.29), but the percentage of the dispersion explained by financial interdependences decreases (0.03). Thus, financial interdependencies are unlikely to be " the factor" in explaining the dispersion of concordances in the area.

Two other suspects are remittances and tourism flows. While remittances and tourism are important components of GDP and employment in some of the countries of the region (e.g. Morocco, Tunisia, Egypt and Jordan), data on these two flows is scant and not very reliable, and this renders a systematic investigation of their relationship with cyclical fluctuations difficult to perform. Finally, it could be that institutions (such as the rule of law, the voice 
and accountability of the political system, etc.) could be important to explain the nature of business cycle fluctuations. Altug et al. (2011) have studied this relationship for a large cross section of developed, developing and emerging markets and found some support for the idea that institutions shape business cycle fluctuations more than standard macroeconomic factors. Their analysis, however, includes only a few Mediterranean countries, and these countries have similar institutions, making it difficult to extend the conclusions to the whole of the basin, where institutional differences turn out to be quite large.

\section{Conclusions}

This paper contributes to the literature in two ways. For students of business cycles, we provide a novel business cycle turning point classification constructed using a standardized methodology and a set of stylized facts summarizing the features of the fluctuations in the Mediterranean. Both could be useful to test domestic and international models of the business cycle, to understand the cyclical characteristics of developed, developing and frontier economies, and to evaluate in which direction existing models need to be modified to capture realistic aspects of Mediterranean fluctuations. For policymakers, we provide a characterization of the cyclical fluctuations in different countries and regions of the Mediterranean, which could help them to formulate policies which better achieve their integration goals, and an interim evaluation of the effects of the Mediterranean partnership.

Overall, the Mediterranean basin is far from an integrated economic area and cyclical fluctuations in the region are driven by considerable idiosyncratic elements. While some cyclical convergence is taking place over time, the process appears to be at the very early stages and not clearly connected with the policy measures that the EU has adopted to foster political and economic integration. At the cost of oversimplifying, the Mediterranean appears to be a colourful archipelago, where islands have its own regional life, are not well interconnected and display heterogeneous cyclical dynamics. There are instances where regional commonalities are important (such as in Mediterranean Europe) but also instances where idiosyncrasies dominates even within regions (such as in the North Africa). Differences across countries and regions appear to be due, in part, to national legislations and institutions and this paper has little to say about those. However, part of the differences seem to be due to structural factors, indicating that a process of homogenization is necessary prior to integration efforts. 
The EU has invested a lot to enhance trade and financial interdependencies, hoping that the homogenization of the economies and their integration would come though these channels. So far the policies do not seem to have achieved their scope. This could be due to the fact that, contrary to other regions of the world, trade and financial interdependencies are only a minor channel of transmission in the region. It could also be the result of the uncertainties about the political process or implementation delays. After all, even though the process started in 1995, it is only since 2007 that the Euro-Mediterranean partnership has been fully shaped. Thus, one may thus just want to wait and see, given that the main trust of the policies is economically sound. Alternatively, one may want to design new measures to reduce national idiosyncrasies. The heterogeneities we have described do not necessarily have an economic reason. Some countries possess natural resources while others do not, some have better productive structures than others, but these difference matter little as cyclical fluctuations are concerned. Institutional and cultural changes are needed, and more can be done on this front.

The interpretative part of the paper has focused attention on how trade and financial interdependencies affect the synchronicity of cyclical fluctuations, because the current literature has stressed their importance in other regions of the world. Trade and financial interdependencies have increased in recent years but other channels could be as or more important to explain the patterns we have found. For example, in many countries migrations are important and remittances are a large portion of GDP. The 2008-09 recession had an important impact on the migrant remittances and on the ability of several non-EU Mediterranean countries to sustain local demand and the current austerity measures are likely to reduce external receipts of many non-EU countries. Similarly, tourism revenues are quite important for certain countries and local employment is heavily skewed toward tourism related sectors. The Arab spring of 2011 has disrupted tourism flows in North Africa and increasing them in Turkey and Spain, thus altering the transmission pattern of cyclical fluctuations in the region. Data on these flows is scarce and reported figures do not necessarily provide the information which is relevant from a cyclical point of view. A better understanding of the interconnections within the Mediterranean could certainly be obtained if reliable data on migration and tourism flows would be available and effort devoted to analyze their international macroeconomic implications. 


\section{References}

Altug, S., M. Enim, and B. Neyapti, 2011. Institutions and Business cycles, manuscript, Koc University.

Bry, G. and C. Boschan, 1971. Cyclical Analysis of Time Series: Procedures and Computer Programs, New York, NBER.

Burns, A. F. and W. C. Mitchell, 1946. Measuring Business Cycles. New York, NBER

CEPR Euro area Business cycle Dating Committee, 2010. Determination of the 2009Q2 through in economic activity, available at www.cepr.org/data/dating/committee.asp

Canova, F. 2007. Methods for Applied Macroeconomic Research, Princeton University Press, Princeton, NJ.

Canova, F. and H. Dellas, 1993. Trade interdependencies and International Business cycles, Journal of International Economics, 34(1-2), 23-47.

Canova, F., M. Ciccarelli, and E. Ortega, 2007. Similarities and Convergence of G-7 Cycles, Journal of Monetary Economics, 54(3), 850-878.

Canova, F., and M. Ciccarelli, 2012. Clubmed? Business cycles in the Mediterranean Basin, forthcoming, Journal of International Economics.

Frankel, J. and A. Rose, 1998. The endogeneity of Optimum Currency Area Criteria, Economic Journal, 108, 1009-1025.

Hamilton, J. D., 2010. Calling Recessions in Real Time, manuscript, Department of Economics, University of California San Diego.

Harding, D. and A. Pagan, 2002. Dissecting the Cycle: A methodological investigation, Journal of Monetary Economics, 59, 319-341.

Harding, D. and A. Pagan, 2006. Synchronization of Cycles, Journal of Econometrics, $132,59-79$.

Imbs, J., 2010. The first global recession in decades, IMF Economic Review, 58(2), $32 \%-35 \%$

NBER Business Cycle Dating Committee, 2008. Determination of the December 2007 Peak in Economic Activity, available at http://www.nber.org/cycles/dec2008.html

Stock, J. and M. Watson, 2010. Estimating turning points using large data sets, NBER working paper 16532 . 
Table 1: National reference cycle turning points

\begin{tabular}{|c|c|c|c|c|}
\hline \multirow[t]{2}{*}{ Country } & \multicolumn{2}{|c|}{ Weighted Mean } & \multicolumn{2}{|c|}{ Median } \\
\hline & Peaks & Troughs & Peaks & Troughs \\
\hline \multirow[t]{6}{*}{ Algeria } & & $1992 \mathrm{q} 3$ & & $1992 \mathrm{q} 3$ \\
\hline & $1993 q^{2}$ & $1997 \mathrm{q} 3$ & $1993 q 2$ & $1997 \mathrm{q} 3$ \\
\hline & $1998 \mathrm{q} 4$ & $1999 \mathrm{q} 3$ & $1998 \mathrm{q} 4$ & $1999 \mathrm{q} 3$ \\
\hline & $2000 \mathrm{q} 3$ & $2001 q 2$ & $2000 \mathrm{q} 3$ & $2001 q 2$ \\
\hline & $2003 q 3$ & $2004 q 2$ & $2003 q 3$ & $2004 q 2$ \\
\hline & $2005 q 1$ & $2005 q 4$ & $2005 q 1$ & $2005 q 4$ \\
\hline \multirow[t]{6}{*}{ Croatia } & & $1991 q 4$ & & $1991 q 4$ \\
\hline & $1992 q 4$ & $1994 q 2$ & $1992 q 4$ & $1994 q 2$ \\
\hline & $1994 q 4$ & $1995 \mathrm{q} 3$ & $1994 q 4$ & $1995 q 3$ \\
\hline & $1997 q 4$ & $1999 \mathrm{q} 2$ & $1997 q 4$ & $1999 \mathrm{q} 1$ \\
\hline & $2005 q 3$ & $2006 q 1$ & $2002 q 4$ & $2006 q 1$ \\
\hline & $2008 \mathrm{q} 3$ & $2009 q 1$ & $2008 \mathrm{q} 3$ & $2009 q 1$ \\
\hline \multirow[t]{5}{*}{ Cyprus } & $1984 q^{2}$ & $1985 q 3$ & $1984 q 2$ & $1985 q 3$ \\
\hline & $1990 \mathrm{q} 2$ & 1991q1 & $1990 \mathrm{q} 2$ & 1991q1 \\
\hline & $1992 q 3$ & $1993 \mathrm{q} 2$ & 1992q3 & $1993 \mathrm{q} 2$ \\
\hline & $1994 q 4$ & $1995 \mathrm{q} 3$ & $1994 q 4$ & $2005 q 2$ \\
\hline & $2008 \mathrm{q} 3$ & & $2008 \mathrm{q} 3$ & \\
\hline \multirow[t]{3}{*}{ Egypt } & & $2004 q 2$ & & $2004 q 2$ \\
\hline & $2005 q 1$ & $2006 q 1$ & $2005 q 1$ & $2006 q 1$ \\
\hline & $2008 q^{2}$ & $2009 q 2$ & $2008 \mathrm{q} 2$ & $2009 q 2$ \\
\hline \multirow[t]{6}{*}{ France } & $1958 \mathrm{q} 1$ & $1958 \mathrm{q} 3$ & $1958 \mathrm{q} 1$ & $1958 \mathrm{q} 3$ \\
\hline & $1974 q 3$ & $1975 q 2$ & $1977 q 1$ & $1977 q 4$ \\
\hline & 1977q1 & $1977 q 3$ & $1979 q 4$ & $1980 \mathrm{q} 4$ \\
\hline & $1979 q 3$ & $1980 q 4$ & 1992q1 & $1993 q 2$ \\
\hline & 1992q1 & $1993 q 3$ & $1998 \mathrm{q} 2$ & $1999 q 4$ \\
\hline & $2008 \mathrm{q} 1$ & $2009 q 1$ & $2008 q 1$ & $2009 q 1$ \\
\hline \multirow[t]{10}{*}{ Greece } & $1961 q 3$ & $1962 q 2$ & 1961q3 & $1962 q 2$ \\
\hline & $1973 q 4$ & $1974 q 3$ & $1972 q 4$ & $1974 q 3$ \\
\hline & $1976 q 4$ & $1977 q 2$ & $1976 q 4$ & $1977 q 2$ \\
\hline & 1980q1 & $1981 q 2$ & $1979 q 3$ & $1981 q 2$ \\
\hline & $1981 q 4$ & $1983 q 2$ & $1984 \mathrm{q} 3$ & $1986 \mathrm{q} 3$ \\
\hline & $1985 q 4$ & $1987 q 2$ & $1989 q 4$ & 1993q1 \\
\hline & 1990q1 & $1990 \mathrm{q} 3$ & $1994 q 2$ & $1994 q 4$ \\
\hline & $1992 q 1$ & $1993 q 1$ & $2008 \mathrm{q} 3$ & \\
\hline & $2000 q^{2}$ & $2001 q 4$ & & \\
\hline & $2008 \mathrm{q} 2$ & & & \\
\hline
\end{tabular}




\begin{tabular}{|c|c|c|c|c|}
\hline \multirow[t]{2}{*}{ Country } & \multicolumn{2}{|c|}{ Weighted Mean } & \multicolumn{2}{|c|}{ Median } \\
\hline & Peaks & Troughs & Peaks & Troughs \\
\hline \multirow[t]{7}{*}{ Israel } & $1958 q^{2}$ & $1959 q 1$ & $1958 \mathrm{q} 2$ & $1959 q 1$ \\
\hline & 1966q1 & $1967 q 2$ & 1966q1 & $1967 q 2$ \\
\hline & $1975 \mathrm{q} 3$ & $1977 q 1$ & $1975 \mathrm{q} 3$ & $1976 q 3$ \\
\hline & $1978 \mathrm{q} 3$ & $1983 q 3$ & $1978 \mathrm{q} 3$ & $1982 q 2$ \\
\hline & 2001q1 & $2001 q 4$ & $2000 q 4$ & $2001 q 4$ \\
\hline & $2002 q 2$ & $2007 q 3$ & $2004 q 4$ & $2005 q 3$ \\
\hline & $2008 \mathrm{q} 2$ & & $2008 \mathrm{q} 2$ & \\
\hline \multirow[t]{12}{*}{ Italy } & $1964 q 1$ & $1964 q 4$ & $1963 q 4$ & $1964 q 3$ \\
\hline & $1967 q 3$ & $1968 \mathrm{q} 3$ & 1968q1 & $1969 q 3$ \\
\hline & 1971q1 & $1972 q 3$ & $1970 \mathrm{q} 1$ & $1971 q 4$ \\
\hline & $1974 q 2$ & $1975 q 3$ & $1974 q 1$ & $1975 q 2$ \\
\hline & $1977 q 1$ & $1977 q 3$ & $1976 q 4$ & $1977 q 2$ \\
\hline & $1978 \mathrm{q} 3$ & $1979 q 2$ & $1978 q 2$ & $1979 q 1$ \\
\hline & $1981 q 2$ & $1982 q 4$ & 1981q3 & $1982 q 3$ \\
\hline & $1992 q 1$ & $1993 q 3$ & $1991 q 4$ & $1993 q 2$ \\
\hline & 1996q1 & $1996 q 4$ & $1995 q 4$ & $1996 q 3$ \\
\hline & 2001q1 & $2001 q 4$ & $2000 q 4$ & 2001q3 \\
\hline & $2002 q 4$ & $2003 q^{2}$ & $2002 q 3$ & $2003 q 1$ \\
\hline & $2007 q 3$ & $2009 q 2$ & $2007 q 2$ & $2009 q 1$ \\
\hline \multirow[t]{3}{*}{ Jordan } & 1993q1 & $1993 q 4$ & 1993q1 & $1993 q 4$ \\
\hline & $1995 q 1$ & $1995 q 3$ & $1995 q 1$ & $1995 q 3$ \\
\hline & $2009 q 3$ & & $2009 q 3$ & \\
\hline \multirow[t]{7}{*}{ Lebanon } & 1994q1 & $1994 q 3$ & 1994q1 & 1994q3 \\
\hline & 1997q1 & $1997 \mathrm{q} 3$ & 1997q1 & $1997 q 3$ \\
\hline & $1999 \mathrm{q} 4$ & 2001q1 & $1999 q 4$ & 2001q1 \\
\hline & $2003 q 2$ & $2004 q 1$ & $2003 q 2$ & $2004 q 1$ \\
\hline & $2004 q 4$ & $2005 q 2$ & $2004 q 4$ & $2005 q 2$ \\
\hline & $2006 q 2$ & $2006 q 4$ & $2006 q 2$ & $2006 q 4$ \\
\hline & $2007 q 3$ & $2008 \mathrm{q} 2$ & $2007 \mathrm{q} 3$ & $2008 \mathrm{q} 2$ \\
\hline \multirow[t]{5}{*}{ Macedonia } & & $1992 \mathrm{q} 3$ & & $1992 q 3$ \\
\hline & 1993q1 & $1995 \mathrm{q} 3$ & 1993q1 & $1995 \mathrm{q} 3$ \\
\hline & $1997 q 4$ & $2004 q 1$ & $1997 q 4$ & $2004 q 1$ \\
\hline & $2004 q 3$ & $2006 q 1$ & $2004 q 3$ & 2006q1 \\
\hline & $2008 \mathrm{q} 3$ & & $2008 \mathrm{q} 3$ & \\
\hline
\end{tabular}




\begin{tabular}{|c|c|c|c|c|}
\hline \multirow[t]{2}{*}{ Country } & \multicolumn{2}{|c|}{ Weighted Mean } & \multicolumn{2}{|c|}{ Median } \\
\hline & Peaks & Troughs & Peaks & Troughs \\
\hline \multirow[t]{5}{*}{ Malta } & & $1997 q 3$ & & $1997 q 3$ \\
\hline & $2000 q 4$ & $2001 q 3$ & $2000 q 3$ & $2001 q 3$ \\
\hline & $2004 q 1$ & $2005 q 1$ & $2008 q^{2}$ & $2009 q 2$ \\
\hline & $2007 q 2$ & $2007 q 4$ & & \\
\hline & $2008 \mathrm{q} 3$ & $2009 q 2$ & & \\
\hline \multirow[t]{6}{*}{ Morocco } & $1991 q 4$ & $1992 \mathrm{q} 2$ & $1991 q^{4}$ & $1992 \mathrm{q} 2$ \\
\hline & $1994 q 4$ & $1995 q 2$ & $1994 q 4$ & $1995 \mathrm{q} 2$ \\
\hline & $1996 q 4$ & $1997 q 2$ & $1996 q 4$ & $1997 q 2$ \\
\hline & $2002 q 2$ & $2003 q 4$ & $2002 q^{2}$ & $2003 q 3$ \\
\hline & $2004 q 3$ & $2005 q 1$ & & \\
\hline & $2008 \mathrm{q} 2$ & $2008 q 4$ & $2008 q^{2}$ & $2008 q 4$ \\
\hline \multirow[t]{9}{*}{ Portugal } & $1968 \mathrm{q} 4$ & $1969 \mathrm{q} 2$ & $1968 q^{4}$ & $1969 \mathrm{q} 2$ \\
\hline & 1974q1 & $1975 q 2$ & $1974 q 1$ & $1975 q 2$ \\
\hline & 1980q1 & $1980 \mathrm{q} 3$ & 1980q1 & 1980q3 \\
\hline & $1983 q 1$ & $1985 q 3$ & $1983 q 1$ & $1985 \mathrm{q} 4$ \\
\hline & 1992q1 & $1994 q 1$ & $1992 q 1$ & $1994 q 1$ \\
\hline & $2002 q 2$ & $2003 q 1$ & $1999 q 2$ & $2000 q 2$ \\
\hline & $2004 q 1$ & $2004 q 4$ & $2002 q^{2}$ & $2002 q 4$ \\
\hline & $2008 \mathrm{q} 2$ & $2009 q 1$ & $2004 q^{2}$ & $2005 q 1$ \\
\hline & & & $2008 q^{2}$ & $2009 q 1$ \\
\hline \multirow[t]{7}{*}{ Serbia } & $1997 q^{4}$ & $1999 q 2$ & $1997 q^{4}$ & $1999 q 2$ \\
\hline & $2000 \mathrm{q} 2$ & $2001 q 4$ & $2000 q^{2}$ & $2001 q 4$ \\
\hline & $2002 q 2$ & $2003 q 4$ & $2002 q^{2}$ & $2003 q 4$ \\
\hline & $2004 q 2$ & $2005 q 1$ & $2004 q^{2}$ & $2005 q 1$ \\
\hline & $2006 q 4$ & $2007 q 4$ & $2006 q^{4}$ & $2007 q 4$ \\
\hline & $2008 \mathrm{q} 2$ & $2009 q 1$ & $2008 q^{2}$ & $2009 q 1$ \\
\hline & $2009 q 3$ & & $2009 q 3$ & \\
\hline \multirow[t]{4}{*}{ Slovenia } & & $1992 \mathrm{q} 3$ & & $1992 \mathrm{q} 3$ \\
\hline & 1994q1 & $1994 q 3$ & 1994q1 & $1997 \mathrm{q} 2$ \\
\hline & 1998q1 & 1999q1 & $2008 \mathrm{q} 3$ & $2009 q 2$ \\
\hline & $2008 \mathrm{q} 3$ & $2009 q 2$ & & \\
\hline \multirow[t]{4}{*}{ Spain } & $1974 q 4$ & 1976q1 & $1974 q^{4}$ & $1975 q 4$ \\
\hline & $1981 \mathrm{q} 2$ & $1982 q 3$ & $1979 q 1$ & $1979 q 4$ \\
\hline & $1991 q 4$ & $1993 q 2$ & $1991 q^{4}$ & $1993 q 2$ \\
\hline & $2007 q 3$ & & $\begin{array}{l}1996 q^{4} \\
2007 q^{2}\end{array}$ & $2001 q 4$ \\
\hline
\end{tabular}




\begin{tabular}{|l|cc|cc|}
\hline Country & \multicolumn{2}{|c|}{ Weighted Mean } & \multicolumn{2}{c|}{ Median } \\
\hline & Peaks & Troughs & Peaks & Troughs \\
\hline Tunisia & $1996 q 4$ & $1997 q 2$ & $1996 q 4$ & $1997 q 2$ \\
& $2001 q 1$ & $2001 q 4$ & $2001 q 1$ & $2001 q 4$ \\
& $2002 q 3$ & $2003 q 4$ & $2002 q 3$ & $2003 q 4$ \\
& $2005 q 2$ & $2005 q 4$ & $2005 q 2$ & $2005 q 4$ \\
& $2008 q 1$ & $2009 q 1$ & $2008 q 1$ & $2009 q 1$ \\
\hline Turkey & $1978 q 3$ & $1979 q 4$ & $1987 q 4$ & $1988 q 4$ \\
& $1987 q 4$ & $1989 q 1$ & $1993 q 4$ & $1994 q 2$ \\
& $1993 q 4$ & $1994 q 2$ & $1998 q 1$ & $1999 q 3$ \\
& $1998 q 3$ & $1999 q 3$ & $2000 q 3$ & $2001 q 3$ \\
& $2000 q 3$ & $2001 q 4$ & $2004 q 3$ & $2005 q 2$ \\
& $2004 q 4$ & $2005 q 4$ & $2008 q 1$ & $2009 q 1$ \\
& $2008 q 1$ & $2009 q 1$ & & \\
\hline
\end{tabular}

When a weighted mean is used and all the series are available the weights used are 0.3 for GDP, 0.25 for unemployment, 0.2 for industrial production, 0.15 on income and 0.1 on sales. When one or more variables are not available weights are adjusted up proportionally such that they add up to one. 
Table 2: Regional and Mediterranean reference cycle turning points

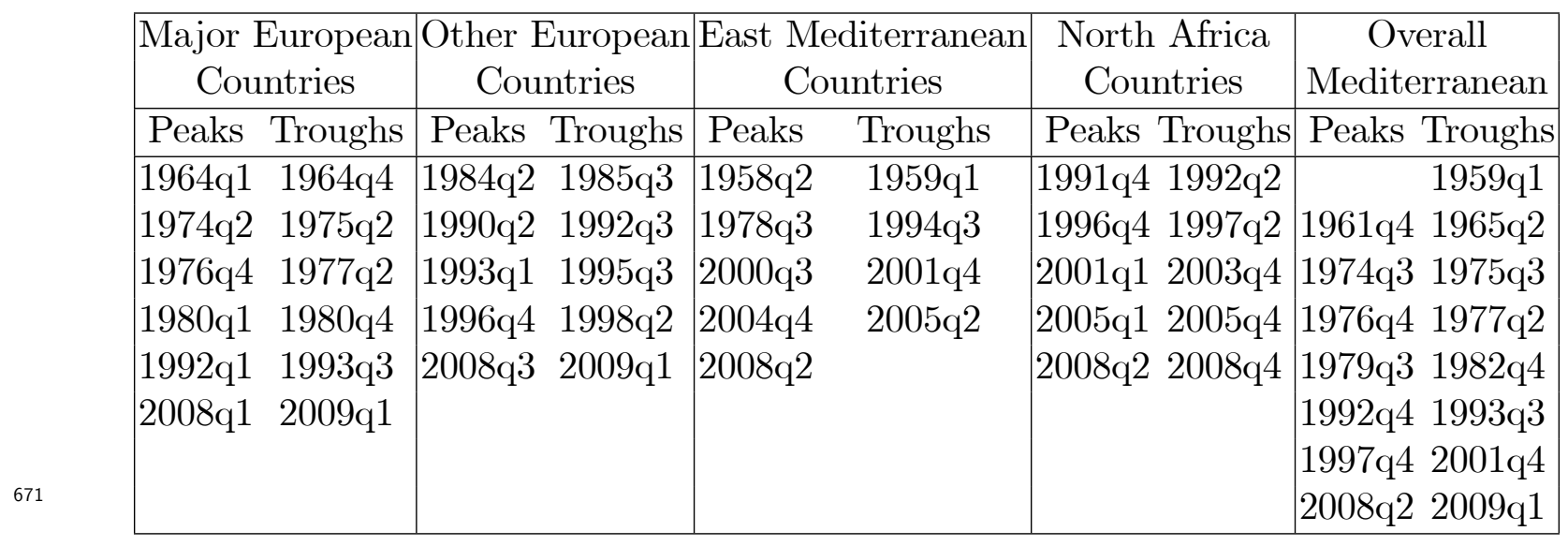

\begin{tabular}{|c|c|c|c|c|}
\hline $\begin{array}{c}\text { Euro } \\
\text { Countries }\end{array}$ & $\begin{array}{l}\text { Non-Euro } \\
\text { Countries }\end{array}$ & & $\begin{array}{l}\text { iich } \\
\text { intries }\end{array}$ & $\begin{array}{c}\text { Poor } \\
\text { Countries }\end{array}$ \\
\hline Peaks Troughs & Peaks Troughs & Peaks & Troughs & Peaks Troughs \\
\hline 1964q1 1964q4 & 1958q2 1959q1 & $1958 \mathrm{q} 2$ & $1959 \mathrm{q} 1$ & 1974q1 1975q2 \\
\hline 1974q2 $1975 q 2$ & 1978q3 1993q4 & $1964 q 1$ & $1964 q 4$ & $1976 q 4$ 1977q2 \\
\hline 1976q4 $1977 q 2$ & $1994 q 4 \quad 1998 q 4$ & $1967 q 3$ & $1968 \mathrm{q} 3$ & $1990 q 2 \quad 1993 q 4$ \\
\hline $1979 q 4 \quad 1982 q 4$ & $2000 q 2 \quad 2004 q 1$ & $1974 q 3$ & $1977 q 3$ & 1997q4 2001q3 \\
\hline 1992q1 1993q3 & $2004 q 4 \quad 2005 q 4$ & $1978 \mathrm{q} 3$ & $1982 q 4$ & $2008 \mathrm{q} 22009 q 1$ \\
\hline 2000q4 2001q4 & $2008 \mathrm{q} 2 \quad 2008 \mathrm{q} 4$ & $1992 \mathrm{q} 1$ & $1993 q 3$ & \\
\hline 2008q2 2009q1 & & $2007 q 4$ & 2009q1 & \\
\hline
\end{tabular}

Notes: Reference cycles turning points are computed equally weighting the turning points of the countries belonging to the region or the area. 
Table 3: Durations and amplitudes of the reference cycle

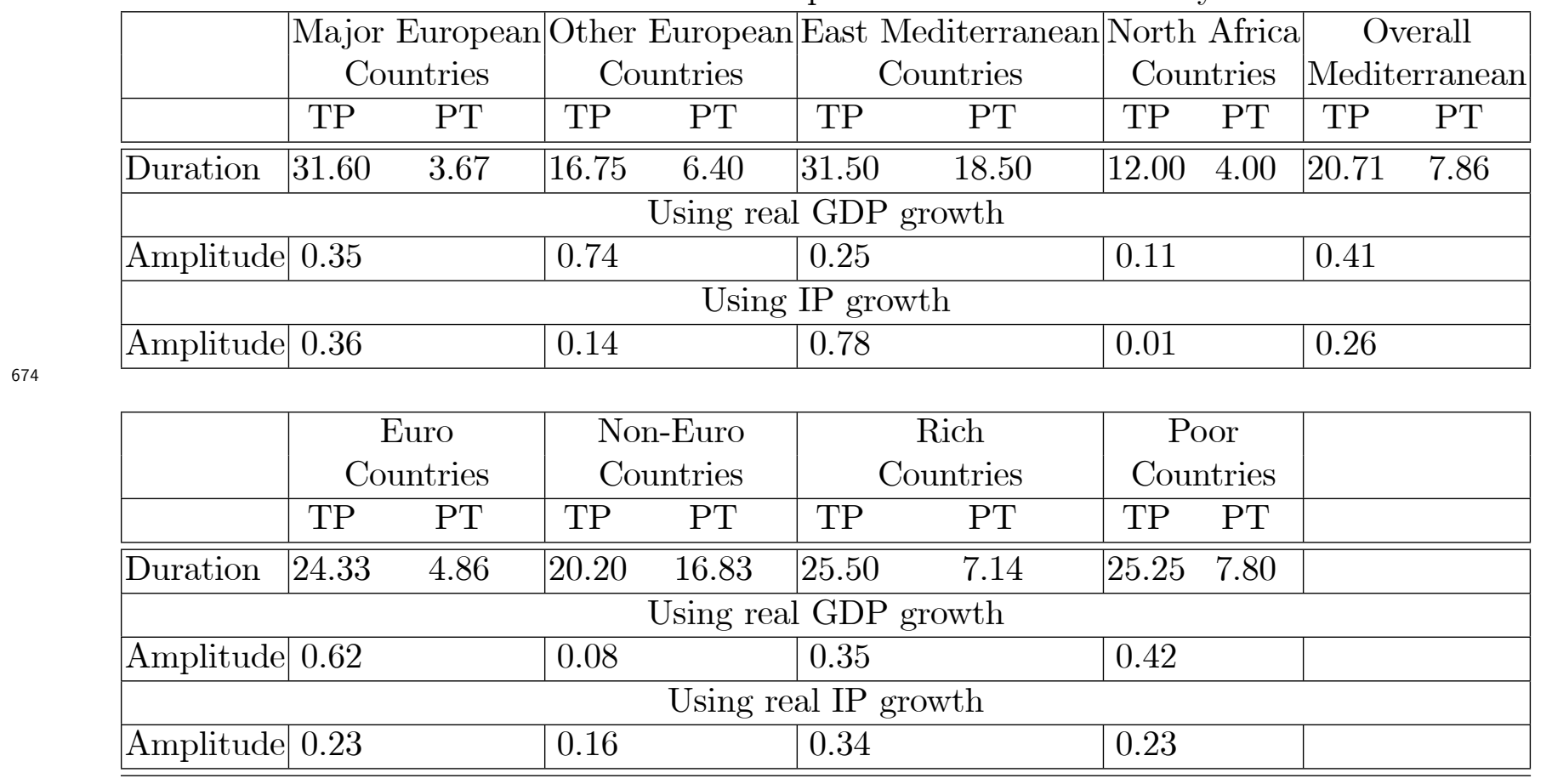

Table 4: Cumulative Output losses in recessions

\begin{tabular}{|l|l|l|l|c|c|c|c|c|c|c|c|c|}
\hline & Average & $\begin{array}{c}\text { Major } \\
\text { European }\end{array}$ & $\begin{array}{c}\text { Other } \\
\text { European }\end{array}$ & Eastern & $\begin{array}{c}\text { North } \\
\text { Africa }\end{array}$ & $\begin{array}{c}\text { Overall } \\
\text { Mediterranean }\end{array}$ & Euro & Non-Euro & Rich & Poor \\
\hline \multicolumn{10}{|c|}{ Using real GDP growth } \\
\hline PT & Actual & -0.06 & -0.02 & 0.52 & 4.38 & 0.04 & 0.60 & -0.11 & 1.69 & 0.07 & 0.53 \\
& TRA & -0.01 & -0.02 & 0.48 & 5.27 & 0.06 & 0.57 & -0.02 & 2.20 & 0.17 & 0.53 \\
\hline \multicolumn{10}{|c|}{ Using IP growth } \\
\hline PT & Actual & -0.25 & -0.14 & -0.13 & 1.34 & 0.03 & 0.23 & -0.17 & 0.78 & 0.09 & 0.17 \\
& TRA & -0.20 & -0.13 & -0.09 & 2.06 & 0.03 & 0.15 & -0.13 & 0.93 & 0.06 & 0.07 \\
\hline
\end{tabular}

TRA refers to the average triangular approximation to cumulative movement. The first column reports the average over time and over countries using the reference cycles of the 19 countries to classify recession; the rest of the columns the average statistics computed over time and countries using the regional reference cycles and for the overall reference cycle. Cumulative movements are measured relative to the previous peak and are in percentages. 
Table 5: Statistics of the reference cycle, subsamples

\begin{tabular}{|c|c|c|c|c|c|c|c|c|c|c|c|}
\hline & & \multicolumn{5}{|c|}{ Using 1995 as cut off date } & \multicolumn{5}{|c|}{ Using 2000 as cut off date } \\
\hline & & \begin{tabular}{|c|} 
Major \\
European
\end{tabular} & \begin{tabular}{|c|} 
Other \\
European
\end{tabular} & $\begin{array}{c}\text { Eastern } \\
\text { Mediterranean }\end{array}$ & $\begin{array}{l}\text { North } \\
\text { Africa }\end{array}$ & Overall & \begin{tabular}{|c|} 
Major \\
European
\end{tabular} & \begin{tabular}{|c|} 
Other \\
European
\end{tabular} & $\begin{array}{c}\text { Eastern } \\
\text { Mediterranean }\end{array}$ & $\begin{array}{l}\text { North } \\
\text { Africa }\end{array}$ & Overall \\
\hline \multicolumn{12}{|c|}{ Durations } \\
\hline Before & TP & 25.00 & 10.50 & 78.00 & & 20.40 & 25.00 & 8.67 & 51.00 & 18.00 & 19.83 \\
\hline & $\mathrm{PT}$ & 3.60 & 8.00 & 33.50 & 2.00 & 7.20 & 3.60 & 7.50 & 33.50 & 2.00 & 7.20 \\
\hline \multirow[t]{2}{*}{ After } & $\mathrm{TP}$ & 58.00 & 23.00 & 16.00 & 12.00 & 21.50 & 58.00 & 41.00 & 12.00 & 10.00 & 26.00 \\
\hline & $\mathrm{PT}$ & 4.00 & 4.00 & 3.50 & 4.50 & 9.50 & 4.00 & 2.00 & 3.50 & 5.33 & 9.50 \\
\hline \multicolumn{12}{|c|}{ Amplitude- GDP growth } \\
\hline Before & TP & 0.32 & 1.44 & & & 0.26 & 0.32 & 0.41 & 0.35 & 0.27 & 0.48 \\
\hline After & $\mathrm{TP}$ & 0.47 & 0.72 & 0.25 & 0.11 & 0.38 & 0.47 & 1.21 & 0.19 & 0.09 & 0.36 \\
\hline \multicolumn{12}{|c|}{ Amplitude-IP growth } \\
\hline Before & TP & 0.38 & 0.04 & 5.01 & \multirow[b]{2}{*}{0.09} & 0.46 & 0.38 & 0.08 & 1.59 & -0.14 & 0.30 \\
\hline \multirow[t]{4}{*}{ After } & $\mathrm{TP}$ & 0.26 & 0.18 & 0.39 & & 0.20 & 0.26 & 0.25 & 0.17 & 0.11 & 0.20 \\
\hline & & & & & & & & & & & \\
\hline & & Euro & Non-Euro & Rich & Poor & & Euro & Non-Euro & Rich & Poor & \\
\hline & & Countries & Countries & Countries & Countries & & Contries & Countries & Countries & Countries & \\
\hline \multicolumn{12}{|c|}{ Durations } \\
\hline Before & $\mathrm{TP}$ & 22.75 & 41.00 & 19.20 & 29.00 & & 24.00 & 29.33 & 19.20 & 24.67 & \\
\hline & PT & 5.40 & 32.00 & 7.50 & 7.00 & & 5.40 & 26.67 & 7.50 & 7.00 & \\
\hline \multirow[t]{2}{*}{ After } & $\mathrm{TP}$ & 27.50 & 6.33 & 57.00 & 21.50 & & 26.00 & 6.50 & 57.00 & 27.00 & \\
\hline & PT & 3.50 & 9.25 & 5.00 & 9.00 & & 3.50 & 7.00 & 5.00 & 9.00 & \\
\hline \multicolumn{12}{|c|}{ Amplitude- GDP growth } \\
\hline Before & $\mathrm{TP}$ & 0.31 & 0.07 & 0.31 & 0.30 & & 1.03 & 0.07 & 0.31 & 0.42 & \\
\hline After & $\mathrm{TP}$ & 0.57 & 0.08 & 0.51 & 0.41 & & 0.27 & 0.10 & 0.51 & 0.47 & \\
\hline \multicolumn{12}{|c|}{ Amplitude-IP growth } \\
\hline Before & $\mathrm{TP}$ & 0.39 & 0.37 & 0.33 & 0.49 & & 0.32 & 0.21 & 0.33 & 0.21 & \\
\hline After & $\mathrm{TP}$ & 0.14 & 0.06 & 0.38 & 0.21 & & 0.09 & 0.08 & 0.38 & 0.22 & \\
\hline
\end{tabular}

Notes: Duration measures average length (in quarters) of cyclical phases; Amplitude measures the average percentage change in GDP or Industrial production in each cyclical phase. TP indicates booms, PT recessions. 

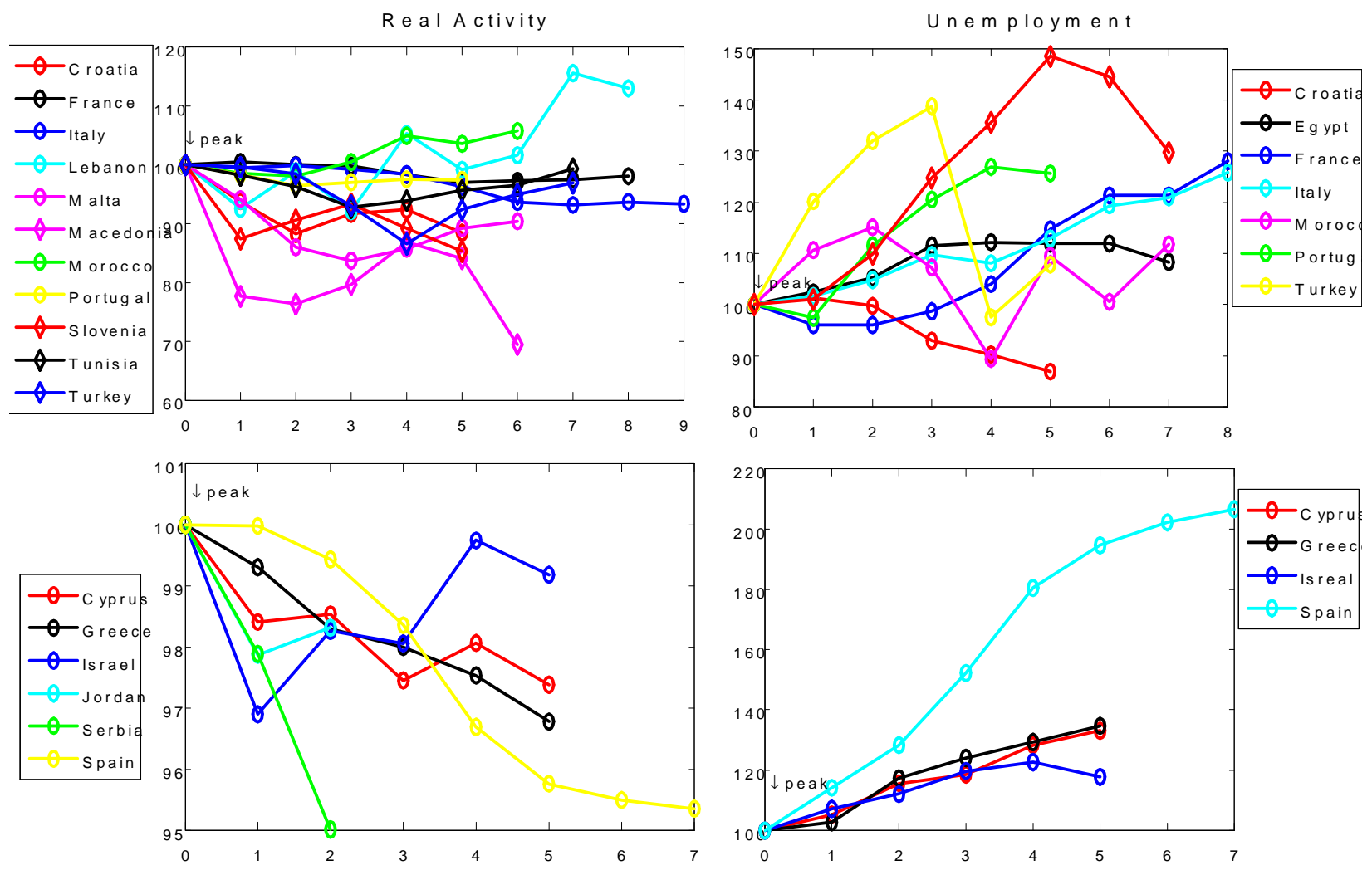

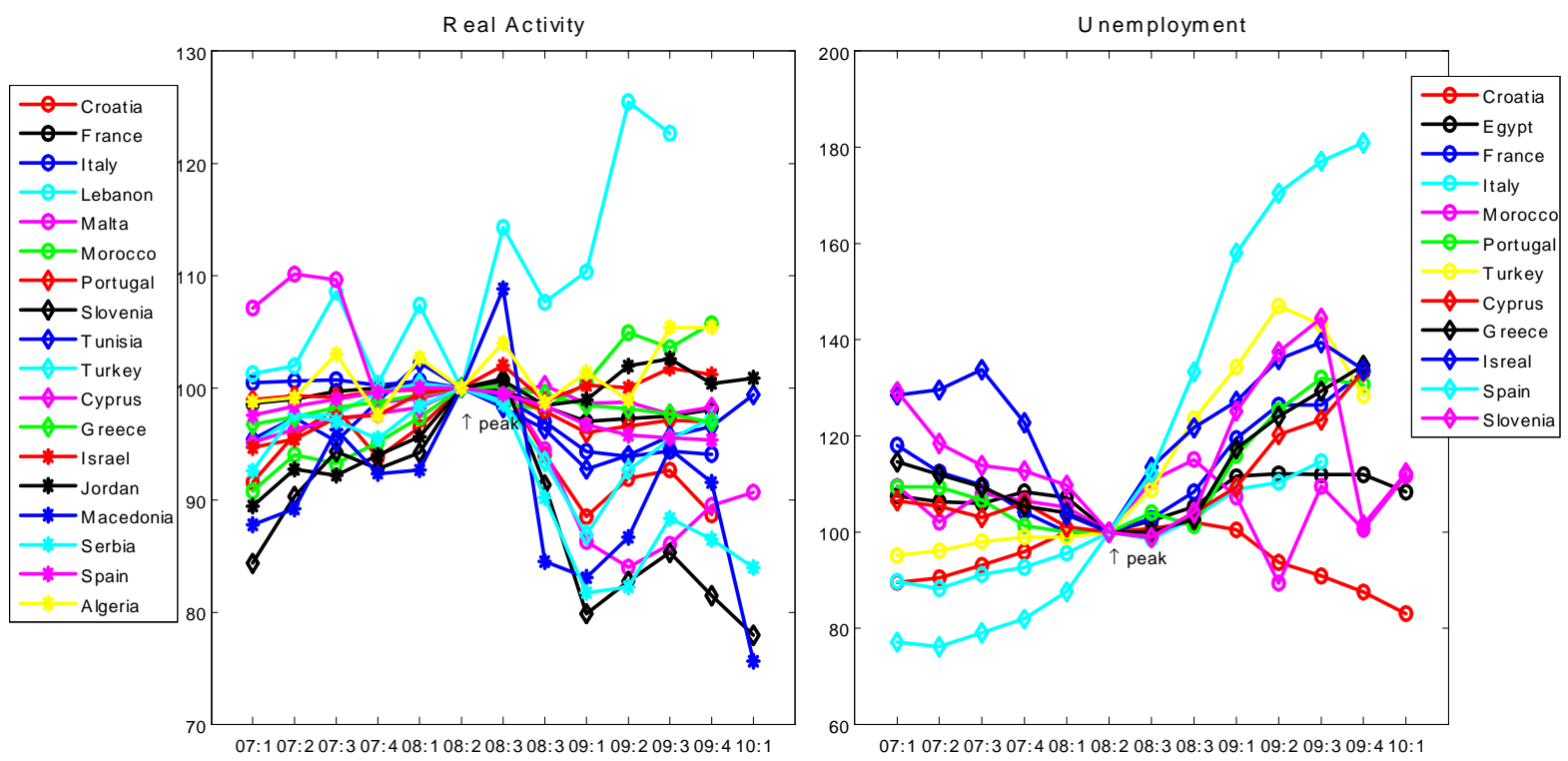

Figure 2: Dynamics around the Mediterranean cyclical peak 
4 CONCLUSIONS

Appendix A: Data sources

\begin{tabular}{|c|c|c|c|c|c|}
\hline & $\begin{array}{l}\text { Real } \\
\text { GDP }\end{array}$ & $\begin{array}{c}\text { Unemployment } \\
\text { Rate }\end{array}$ & $\begin{array}{l}\text { Industrial } \\
\text { Production }\end{array}$ & $\begin{array}{c}\text { Real } \\
\text { Income }\end{array}$ & Sales \\
\hline Algeria & & & $\begin{array}{c}1993 q 1-2009 q 4 \\
\text { (IFS) }\end{array}$ & & \\
\hline Croatia & $\begin{array}{c}\text { 1993q1-2009q4 } \\
\text { (IFS) }\end{array}$ & $\begin{array}{c}2003 \mathrm{q} 1-2010 \mathrm{q} 1 \\
\text { (IFS) }\end{array}$ & $\begin{array}{c}1990 q 1-2010 q 1 \\
\text { (IFS) }\end{array}$ & $\begin{array}{c}2000 q 1-2009 q 3 \\
\text { (Eurostat) }\end{array}$ & \\
\hline Cyprus & $\begin{array}{c}\text { 1995q1-2010q1 } \\
\text { (IFS) }\end{array}$ & $\begin{array}{c}2004 q 1-2010 q 1 \\
\text { (IFS) }\end{array}$ & $\begin{array}{c}1980 q 1-2010 q 1 \\
\text { (IFS) }\end{array}$ & $\begin{array}{c}\text { 1995q1-2010q1 } \\
\text { (Eurostat) }\end{array}$ & \\
\hline Egypt & $\begin{array}{c}2002 q 1-2010 q 1 \\
\text { (IFS) }\end{array}$ & $\begin{array}{c}2003 q 1-2010 q 1 \\
\text { (IFS) }\end{array}$ & & & \\
\hline France & $\begin{array}{c}1949 q 1-2009 q 4 \\
\text { (OECD) }\end{array}$ & $\begin{array}{c}1967 q 4-2010 q 1 \\
(\text { OECD) }\end{array}$ & $\begin{array}{c}1957 q 1-2010 q 1 \\
\text { (IFS) }\end{array}$ & $\begin{array}{c}1978 \mathrm{q} 1-2010 \mathrm{q} 1 \\
\text { (Eurostat) }\end{array}$ & $\begin{array}{c}\text { 1975q1-2010q1 } \\
\text { (OECD) }\end{array}$ \\
\hline Greece & $\begin{array}{c}1960 q 1-2009 q 4 \\
\text { (OECD) }\end{array}$ & $\begin{array}{c}1998 \mathrm{q} 1-2009 \mathrm{q} 4 \\
(\text { OECD })\end{array}$ & $\begin{array}{c}1995 q 1-2010 q 1 \\
\text { (IFS) }\end{array}$ & $\begin{array}{c}2000 q 1-2009 q 4 \\
\text { (Eurostat) }\end{array}$ & $\begin{array}{c}1963 q 1-2009 q 4 \\
\text { (OECD) }\end{array}$ \\
\hline Israel & $\begin{array}{c}\text { 1968q1-2009q4 } \\
\text { (IFS) }\end{array}$ & $\begin{array}{c}1992 \mathrm{q} 1-2009 \mathrm{q} 4 \\
(\text { OECD })\end{array}$ & $\begin{array}{c}1957 q 1-2010 q 1 \\
\text { (IFS) }\end{array}$ & & \\
\hline Italy & $\begin{array}{c}1960 \mathrm{q} 1-2009 \mathrm{q} 4 \\
\text { (OECD) }\end{array}$ & $\begin{array}{c}1959 \mathrm{q} 1-2009 \mathrm{q} 4 \\
(\mathrm{OECD})\end{array}$ & $\begin{array}{c}1957 q 1-2010 q 1 \\
\text { (IFS) }\end{array}$ & $\begin{array}{c}\text { 1981q1-2010q1 } \\
\text { (Eurostat) }\end{array}$ & $\begin{array}{c}1990 q 1-2009 q 4 \\
\text { (OECD) }\end{array}$ \\
\hline Jordan & $\begin{array}{c}\text { 1992q1-2010q1 } \\
\text { (MCData) }\end{array}$ & & & & \\
\hline Lebanon & & & $\begin{array}{c}\text { 1993q1-2010q1 } \\
\text { (CB) }\end{array}$ & & \\
\hline Macedonia & & & $\begin{array}{c}\text { 1992q1-2010q1 } \\
\text { (IFS) }\end{array}$ & & \\
\hline Malta & & & $\begin{array}{c}\text { 1997q1-2010q1 } \\
\text { (IFS) }\end{array}$ & $\begin{array}{c}2000 q 1-2009 q 4 \\
\text { (Eurostat) }\end{array}$ & \\
\hline Morocco & $\begin{array}{c}\text { 1990q1-2009q4 } \\
\text { (IFS) }\end{array}$ & $\begin{array}{c}1996 \mathrm{q} 1-2010 \mathrm{q} 1 \\
\text { (IFS) }\end{array}$ & $\begin{array}{c}1999 q 1-2009 q 3 \\
(\mathrm{CB})\end{array}$ & & \\
\hline Portugal & $\begin{array}{c}1960 \mathrm{q} 1-2009 \mathrm{q} 4 \\
\text { (OECD) }\end{array}$ & $\begin{array}{c}1983 q 2-2009 q 4 \\
(\text { OECD })\end{array}$ & $\begin{array}{c}1957 q 1-2010 q 1 \\
\text { (IFS) }\end{array}$ & $\begin{array}{c}1995 q 1-2009 q 4 \\
\text { (Eurostat) }\end{array}$ & $\begin{array}{c}1990 \mathrm{q} 1-2009 \mathrm{q} 4 \\
\text { (OECD) }\end{array}$ \\
\hline Serbia & & & $\begin{array}{c}1994 q 1-2010 q 1 \\
\text { (IFS) }\end{array}$ & & \\
\hline Slovenia & $\begin{array}{c}\text { 1992q1-2010q1 } \\
\text { (IFS) }\end{array}$ & $\begin{array}{c}\text { 1997q2-2010q1 } \\
\text { (IFS) }\end{array}$ & $\begin{array}{c}1992 q 1-2010 q 1 \\
\text { (IFS) }\end{array}$ & $\begin{array}{c}1995 q 1-2009 q 4 \\
\text { (Eurostat) }\end{array}$ & \\
\hline Spain & $\begin{array}{c}1960 q 1-2009 q 4 \\
\text { (OECD) }\end{array}$ & $\begin{array}{c}1972 q 1-2009 q 4 \\
(\text { OECD })\end{array}$ & $\begin{array}{c}1961 q 1-2010 q 1 \\
\text { (IFS) }\end{array}$ & $\begin{array}{c}1995 q 1-2010 q 4 \\
\text { (Eurostat) }\end{array}$ & $\begin{array}{c}1995 q 1-2009 q 4 \\
\text { (OECD) }\end{array}$ \\
\hline Tunisia & & & $\begin{array}{c}1993 \mathrm{q} 1-2010 \mathrm{q} 4 \\
\text { (IFS) }\end{array}$ & & \\
\hline Turkey & $\begin{array}{c}1960 \mathrm{q} 1-2009 \mathrm{q} 4 \\
(\mathrm{OECD})\end{array}$ & $\begin{array}{c}2000 \mathrm{q} 1-2009 \mathrm{q} 4 \\
(\mathrm{OECD})\end{array}$ & $\begin{array}{c}1980 \mathrm{q} 1-2010 \mathrm{q} 1 \\
\text { (IFS) }\end{array}$ & & \\
\hline
\end{tabular}


Notes: IFS stands for IMF International Financial Statistics; OECD stands for OECD Quarterly National Accounts, except for the unemployment rates and sales, both of which are from the OECD Main Economic Indicators (the Labor Force Statistics and the Production \& Sales Database, respectively); Eurostat stands for the Eurostat Quarterly National Accounts; CB stands for Central Bank data. For Lebanon industrial production measures electricity production. Real GDP and real income are measured in local currency; unemployment rates are calculated over the total labor force. Bilateral trade data is from direction of trade (DOT) database at the IMF. Bilateral capital flows are from the Country Portofolio Investment Survey database at the IMF and refer to 2007 flows. 


\section{Appendix B: Turning points individual series}

Table B.1: Individual series turning points.

Minimum cycle length of 5 quarters, minimum phase length of 2 quarters.

\begin{tabular}{|c|c|c|c|c|c|}
\hline & Real GDP & Unemployment & Ind. Prod & Real Income & Sales \\
\hline & Peaks Troughs & Peaks Troughs & Peaks Troughs & Peaks Troughs & Peaks Troughs \\
\hline Algeria & & & $\begin{array}{ll} & 1992 q 3 \\
1993 q 2 & 1997 q 3 \\
1998 q 4 & 1999 q 3 \\
2000 q 3 & 2001 q 2 \\
2003 q 3 & 2004 q 2 \\
2005 q 1 & 2005 q 4\end{array}$ & & \\
\hline Croatia & $\begin{array}{ll}1994 q 4 & 1995 q 3 \\
1997 q 4 & 1999 q 2 \\
2002 q 3 & 2003 q 1 \\
2005 q 3 & 2006 q 1 \\
2008 q 3 & 2009 q 1\end{array}$ & $2008 \mathrm{q} 4$ & $\begin{array}{ll} & 1991 q 4 \\
1992 q 4 & 1994 q 2 \\
1995 q 1 & 1995 q 3 \\
1997 q 4 & 1999 q 1 \\
1999 q 4 & 2000 q 2 \\
2003 q 3 & 2004 q 1 \\
2005 q 2 & 2006 q 1 \\
2007 q 3 & \end{array}$ & $\begin{array}{rl}2000 q 3 \\
2008 q 3 & 2009 q 1\end{array}$ & \\
\hline Cyprus & $2008 q 44^{1995 q 3}$ & $\begin{array}{rr}2005 q 3 \\
2006 q 1 & 2006 q 4 \\
2008 q 3 & \end{array}$ & $\begin{array}{ll}1984 q 2 & 1985 q 3 \\
1990 q 2 & 1991 q 1 \\
1992 q 3 & 1993 q 2 \\
1995 q 1 & 1996 q 3 \\
2000 q 1 & 2000 q 4 \\
2004 q 1 & 2005 q 2 \\
2007 q 4 & 2009 q 2\end{array}$ & $2008 q 3$ & \\
\hline Egypt & & $\begin{array}{rr} & 2004 q 2 \\
2005 q 1 & 2006 q 1 \\
2008 q 2 & 2009 q 2\end{array}$ & & & \\
\hline France & \begin{tabular}{|ll}
$1958 q 1$ & $1958 q 3$ \\
$1974 q 3$ & $1975 q 2$ \\
$1980 q 1$ & $1980 q 4$ \\
$1992 q 1$ & $1993 q 1$ \\
$2008 q 1$ & $2009 q 1$ \\
\end{tabular} & $\begin{array}{ll} & 1968 q 2 \\
1969 q 2 & 1973 q 3 \\
1974 q 2 & 1977 q 3 \\
1978 q 1 & 1987 q 2 \\
1990 q 2 & 1994 q 2 \\
1995 q 2 & 1997 q 2 \\
1998 q 1 & 1998 q 4 \\
2001 q 3 & 2006 q 1 \\
2008 q 1 & \end{array}$ & $\begin{array}{lll}1958 q 1 & 1959 q 1 \\
1966 q 3 & 1967 q 1 \\
1974 q 3 & 1975 q 3 \\
1977 q 1 & 1977 q 4 \\
1979 q 3 & 1980 q 4 \\
1981 q 4 & 1982 q 3 \\
1985 q 1 & 1985 q 3 \\
1990 q 3 & 1991 q 2 \\
1992 q 1 & 1993 q 3 \\
2000 q 4 & 2003 q 2 \\
2004 q 4 & 2005 q 3 \\
2008 q 1 & 2009 q 2\end{array}$ & $\begin{array}{ll}1980 q 1 & 1980 q 4 \\
1992 q 1 & 1993 q 2 \\
2008 q 1 & 2009 q 1\end{array}$ & 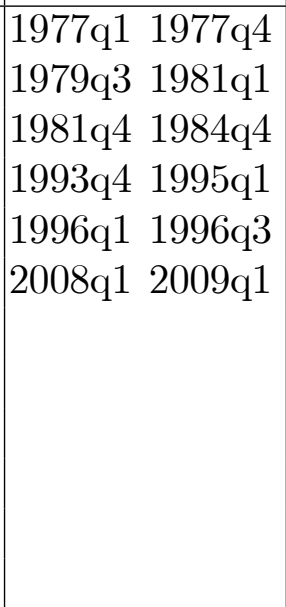 \\
\hline
\end{tabular}




\begin{tabular}{|c|c|c|c|c|c|}
\hline & Real GDP & Unemployment & Ind. Prod & Real Income & Sales \\
\hline & Peaks Troughs & Peaks Troughs & Peaks Troughs & Peaks Troughs & Peaks Troughs \\
\hline \multirow[t]{13}{*}{ Greece } & 1961q3 1962q2 & $1999 q 4$ & 1995q4 1997q3 & \multirow{13}{*}{$2008 q 3$} & 1963q3 1964q1 \\
\hline & $1973 q 4$ 1974q3 & 2001q1 2001q4 & $2000 q 22002 q 3$ & & 1966q3 1967q1 \\
\hline & 1976q4 1977q2 & $2003 q 22004 q 1$ & $2004 q 22004 q 4$ & & 1970q3 1971q2 \\
\hline & 1980q1 1981q2 & $2005 q 12005 q 3$ & $2007 q 1$ & & $1972 q 4$ 1974q3 \\
\hline & 1981q4 1983q2 & 2006q32 2007q1 & & & 1977q3 1978q2 \\
\hline & $1985 q 4$ 1987q2 & $2008 q 2$ & & & 1979q3 1982q2 \\
\hline & 1990q1 1990q3 & & & & 1984q3 1986q3 \\
\hline & 1992q1 1993q1 & & & & 1988q3 1989q1 \\
\hline & 1994q3 1995q2 & & & & 1989q4 1992q1 \\
\hline & $2008 q 3$ & & & & 1992q3 1993q2 \\
\hline & & & & & 1994q2 1994q4 \\
\hline & & & & & 2006q3 2007q1 \\
\hline & & & & & 2008q1 2009q2 \\
\hline \multirow[t]{10}{*}{ Israel } & 1975q3 1977q1 & $1992 \mathrm{q} 3$ & 1958q2 1959q1 & & \\
\hline & 1978q3 1983q3 & 1996q2 2000q3 & 1966q1 1967q2 & & \\
\hline & $2008 \mathrm{q} 3$ & 2001q1 2001q4 & $1975 q 3$ 1976q3 & & \\
\hline & & $2007 q 12007 q 3$ & 1979q2 1980q1 & & \\
\hline & & $2008 q 2$ & 1981q2 1982q2 & & \\
\hline & & & $1987 q 4$ 1989q2 & & \\
\hline & & & 1990q3 1991q1 & & \\
\hline & & & 2000q3 2001q4 & & \\
\hline & & & $2002 q 22003 q 3$ & & \\
\hline & & & $2008 q 22009 q 2$ & & \\
\hline \multirow[t]{15}{*}{ Italy } & 1964q1 1964q4 & $1963 q 41966 q 3$ & 1964q1 1964q3 & 1981q4 1982q4 & $1990 q 4$ 1992q4 \\
\hline & 1974q3 1975q2 & 1967q3 1968q3 & 1969q2 1971q2 & 1992q1 1993q3 & 1993q3 1994q2 \\
\hline & 1977q1 1977q3 & 1971q1 1972q3 & $1974 q 2$ 1975q3 & 1996q1 1996q4 & 1995q2 1996q3 \\
\hline & 1981q4 1982q4 & 1974q2 $1977 q 3$ & $1976 q 4$ 1978q1 & 2001q1 2001q4 & $1999 q 42004 q 3$ \\
\hline & 1992q1 1993q3 & 1978q3 1979q3 & $1978 q 4$ 1979q2 & $2002 q 42003 q 2$ & 2006q32 2008q4 \\
\hline & 1996q1 1996q4 & 1981q1 1984q1 & 1980q1 1980q3 & $2008 q 12009 q 2$ & \\
\hline & 2001q1 2001q4 & $1984 q 31987 q 4$ & 1981q2 1983q2 & & \\
\hline & $2002 q 42003 q 2$ & 1988q3 1989q2 & $1984 q 3$ 1985q1 & & \\
\hline & 2004q3 2005q1 & 1991q3 1996q4 & $1989 q 4$ 1991q2 & & \\
\hline & $2007 q 32009 q 2$ & 1997q3 1998q2 & 1992q1 1993q3 & & \\
\hline & & $2002 q 12003 q 1$ & $1995 q 4$ 1996q4 & & \\
\hline & & $2007 q 2$ & $1997 q 4$ 1999q2 & & \\
\hline & & & $2000 q 42001 q 4$ & & \\
\hline & & & $2002 q 42005 q 1$ & & \\
\hline & & & $2007 q 32009 q 2$ & & \\
\hline \multirow[t]{3}{*}{ Jordan } & 1993q1 1993q4 & & & & \\
\hline & 1995q1 1995q3 & & & & \\
\hline & $2009 q 3$ & & & & \\
\hline
\end{tabular}




\begin{tabular}{|c|c|c|c|c|c|}
\hline & Real GDP & Unemployment & Ind. Prod & Real Income & Sales \\
\hline & Peaks Troughs & Peaks Troughs & Peaks Troughs & Peaks Troughs & Peaks Troughs \\
\hline Lebanon & & & $\begin{array}{ll}1994 q 1 & 1994 q 3 \\
1997 q 1 & 1997 q 3 \\
1999 q 4 & 2001 q 1 \\
2003 q 2 & 2004 q 1 \\
2004 q 4 & 2005 q 2 \\
2006 q 2 & 2006 q 4 \\
2007 q 3 & 2008 q 2\end{array}$ & & \\
\hline Macedonia & & & $\begin{array}{ll} & 1992 q 3 \\
1993 q 1 & 1995 q 3 \\
1997 q 4 & 2004 q 1 \\
2004 q 3 & 2006 q 1 \\
2008 q 3 & \end{array}$ & & \\
\hline Malta & & & $\begin{array}{ll} & 1997 q 3 \\
2000 q 4 & 2001 q 3 \\
2004 q 1 & 2005 q 1 \\
2007 q 2 & 2007 q 4 \\
2008 q 3 & 2009 q 2\end{array}$ & $\begin{array}{ll}2000 q 3 & 2003 q 1 \\
2008 q 2 & 2009 q 2\end{array}$ & \\
\hline Morocco & $\begin{array}{lll}1991 q 4 & 1992 q 2 \\
1994 q 4 & 1995 q 2 \\
1996 q 4 & 1997 q 2 \\
2008 q 2 & 2008 q 4\end{array}$ & \begin{tabular}{|ll}
$1997 q 2$ & $1998 q 1$ \\
$2002 q 2$ & $2003 q 4$ \\
$2004 q 3$ & $2005 q 1$ \\
$2006 q 2$ & $2006 q 4$ \\
$2009 q 2$ &
\end{tabular} & $\begin{array}{ll}2002 q 3 & 2003 q 1 \\
2008 q 2 & 2008 q 4\end{array}$ & & \\
\hline Portugal & $\begin{array}{ll}1968 q 4 & 1969 q 2 \\
1974 q 1 & 1975 q 2 \\
1980 q 1 & 1980 q 3 \\
1983 q 1 & 1984 q 2 \\
1992 q 1 & 1993 q 1 \\
2002 q 2 & 2002 q 4 \\
2004 q 2 & 2004 q 4 \\
2008 q 2 & 2009 q 1\end{array}$ & $\begin{array}{ll} & 1986 q 1 \\
1991 q 2 & 1996 q 2 \\
1998 q 2 & 1999 q 2 \\
2000 q 4 & 2003 q 2 \\
2004 q 1 & 2005 q 4 \\
2006 q 2 & 2007 q 2 \\
2008 q 1 & \end{array}$ & $\begin{array}{ll}1964 q 4 & 1965 q 2 \\
1966 q 2 & 1967 q 1 \\
1970 q 2 & 1971 q 1 \\
1974 q 1 & 1975 q 3 \\
1980 q 1 & 1980 q 3 \\
1983 q 1 & 1983 q 3 \\
1984 q 3 & 1985 q 3 \\
1990 q 4 & 1991 q 2 \\
1992 q 1 & 1994 q 1 \\
1999 q 4 & 2000 q 2 \\
2001 q 3 & 2005 q 2 \\
2007 q 1 & 2009 q 1\end{array}$ & $\begin{array}{ll}2002 q 2 & 2002 q 4 \\
2004 q 2 & 2004 q 4 \\
2008 q 2 & 2009 q 1\end{array}$ & \begin{tabular}{|ll}
$1993 q 3$ & $1994 q 2$ \\
$2000 q 2$ & $2001 q 1$ \\
$2002 q 3$ & $2003 q 1$ \\
$2008 q 3$ & $2009 q 1$
\end{tabular} \\
\hline Serbia & & & $\begin{array}{ll}1997 q 4 & 1999 q 2 \\
2000 q 2 & 2001 q 4 \\
2002 q 2 & 2003 q 4 \\
2004 q 2 & 2005 q 1 \\
2006 q 4 & 2007 q 4 \\
2008 q 2 & 2009 q 1 \\
2009 q 3\end{array}$ & & \\
\hline
\end{tabular}




\begin{tabular}{|c|c|c|c|c|c|}
\hline & Real GDP & Unemployment & Ind. Prod & Real Income & Sales \\
\hline & Peaks Troughs & Peaks Troughs & Peaks Troughs & Peaks Troughs & Peaks Troughs \\
\hline Slovenia & 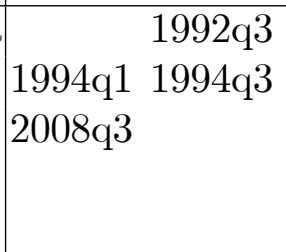 & \begin{tabular}{|ll} 
& $1999 q 1$ \\
$2000 q 3$ & $2001 q 1$ \\
$2003 q 2$ & $2004 q 1$ \\
$2004 q 3$ & $2006 q 1$ \\
$2008 q 3$ & $2009 q 3$
\end{tabular} & $\begin{array}{ll} & 1993 q 2 \\
1995 q 1 & 1995 q 4 \\
1998 q 1 & 1999 q 2 \\
2008 q 2 & 2009 q 2\end{array}$ & $2008 q 32009 q 1$ & \\
\hline Spain & $\begin{array}{lll}1974 q 4 & 1975 q 2 \\
1978 q 2 & 1979 q 1 \\
1980 q 4 & 1981 q 2 \\
1992 q 1 & 1993 q 2 \\
2008 q 1 & \end{array}$ & $\begin{array}{ll} & 1985 q 3 \\
1987 q 4 & 1988 q 2 \\
1991 q 1 & 1994 q 2 \\
2001 q 3 & 2003 q 1 \\
2005 q 3 & 2006 q 1 \\
2007 q 2 & \end{array}$ & 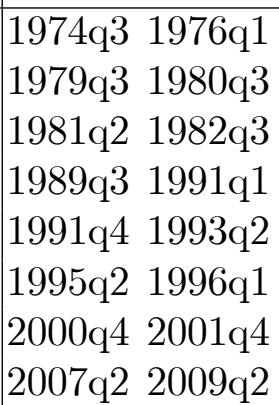 & $2008 q 1$ & $2007 \mathrm{q} 3{ }^{1996 q 2}$ \\
\hline Tunisia & & & $\begin{array}{lll}\text { 1996q4 } & 1997 q 2 \\
2001 q 1 & 2001 q 4 \\
2002 q 3 & 2003 q 4 \\
2005 q 2 & 2005 q 4 \\
2008 q 1 & 2009 q 1\end{array}$ & & \\
\hline Turkey & $\begin{array}{ll}1978 q 3 & 1980 q 2 \\
1987 q 4 & 1989 q 1 \\
1993 q 4 & 1994 q 2 \\
1998 q 3 & 1999 q 3 \\
2000 q 4 & 2001 q 4 \\
2008 q 1 & 2009 q 1\end{array}$ & $\begin{array}{ll}2000 q 3 & 2003 q 2 \\
2004 q 4 & 2005 q 4 \\
2006 q 4 & 2009 q 2\end{array}$ & $\begin{array}{ll}1988 q 1 & 1988 q 4 \\
1993 q 4 & 1994 q 2 \\
1998 q 1 & 1999 q 3 \\
2000 q 3 & 2001 q 2 \\
2004 q 2 & 2005 q 1 \\
2008 q 1 & 2009 q 1\end{array}$ & & \\
\hline
\end{tabular}


Table B.2: Individual series turning points.

Minimum cycle length of 7 quarters, minimum phase length of 3 quarters.

\begin{tabular}{|c|c|c|c|c|c|}
\hline & Real GDP & Unemployment & Ind. Prod & Real Income & Sales \\
\hline & Peaks Troughs & Peaks Troughs & Peaks Troughs & Peaks Troughs & Peaks Troughs \\
\hline Algeria & & & $\begin{array}{ll}1993 q 2 & 1997 q 3 \\
1998 q 4 & 1999 q 3 \\
2000 q 3 & 2001 q 2 \\
2002 q 3 & 2004 q 2\end{array}$ & & \\
\hline Croatia & $\begin{array}{ll}1994 q 4 & 1995 q 3 \\
1997 q 4 & 1999 q 2 \\
2008 q 3 & \end{array}$ & $2008 q 4$ & $\begin{array}{ll} & 1991 q 4 \\
1992 q 4 & 1994 q 2 \\
1997 q 4 & 1999 q 1 \\
2005 q 2 & 2006 q 1 \\
2008 q 2 & \end{array}$ & & \\
\hline Cyprus & $2008 \mathrm{q} 4$ & $2008 \mathrm{q} 3{ }^{2006 \mathrm{q} 4}$ & $\begin{array}{ll}1984 q 2 & 1985 q 3 \\
1990 q 2 & 1991 q 1 \\
1992 q 3 & 1993 q 2 \\
1995 q 4 & 1997 q 3 \\
2000 q 1 & 2000 q 4 \\
2007 q 4 & 2009 q 2\end{array}$ & $2008 \mathrm{q} 3$ & \\
\hline Egypt & & $\begin{array}{rr}2004 q 2 \\
2005 q 1 & 2006 q 1 \\
2008 q 2 & 2009 q 2\end{array}$ & & & \\
\hline France & $\begin{array}{ll}1974 q 3 & 1975 q 2 \\
1980 q 1 & 1980 q 4 \\
1992 q 1 & 1993 q 1 \\
2008 q 1 & 2009 q 1\end{array}$ & $\begin{array}{ll}1969 q 2 & 1973 q 3 \\
1974 q 2 & 1987 q 2 \\
1990 q 2 & 1994 q 2 \\
1995 q 2 & 1997 q 2 \\
1998 q 1 & 1999 q 1 \\
2001 q 3 & 2006 q 1 \\
2008 q 1 & \end{array}$ & 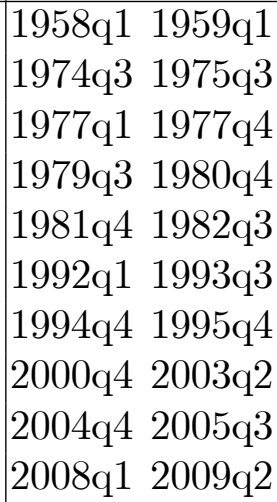 & $\begin{array}{ll}1980 \mathrm{q} 1 & 1980 \mathrm{q} 4 \\
\text { 1992q1 } & 1993 \mathrm{q} 2 \\
\text { 2008q1 } & 2009 \mathrm{q} 1\end{array}$ & 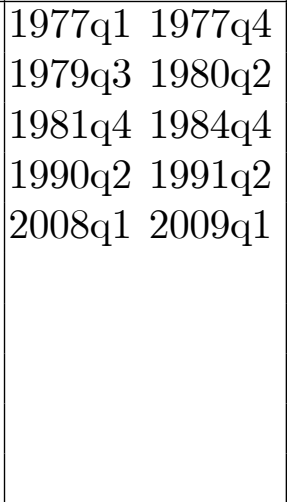 \\
\hline Greece & 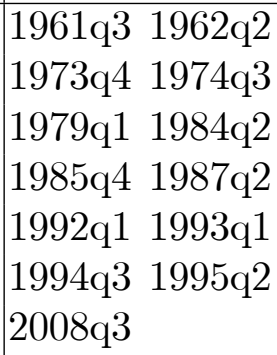 & \begin{tabular}{|lr} 
& $1999 q 4$ \\
$2001 q 1$ & $2001 q 4$ \\
$2003 q 2$ & $2004 q 1$ \\
$2008 q 2$ &
\end{tabular} & 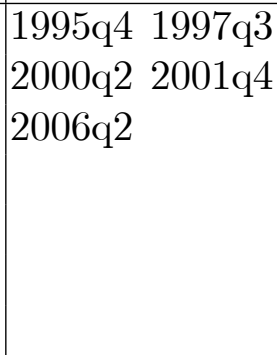 & $2008 \mathrm{q} 3$ & 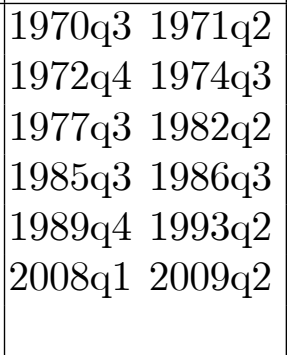 \\
\hline
\end{tabular}




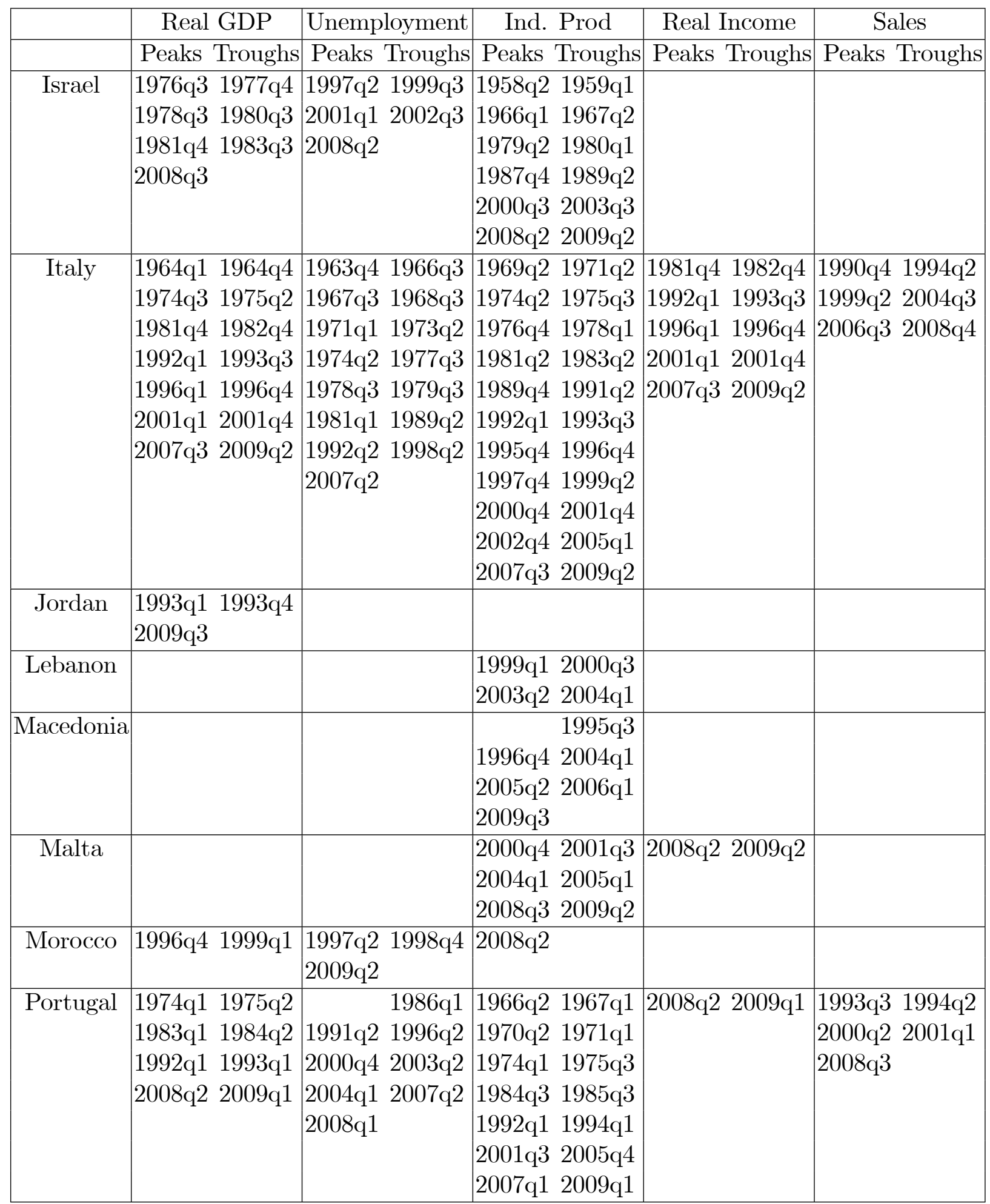




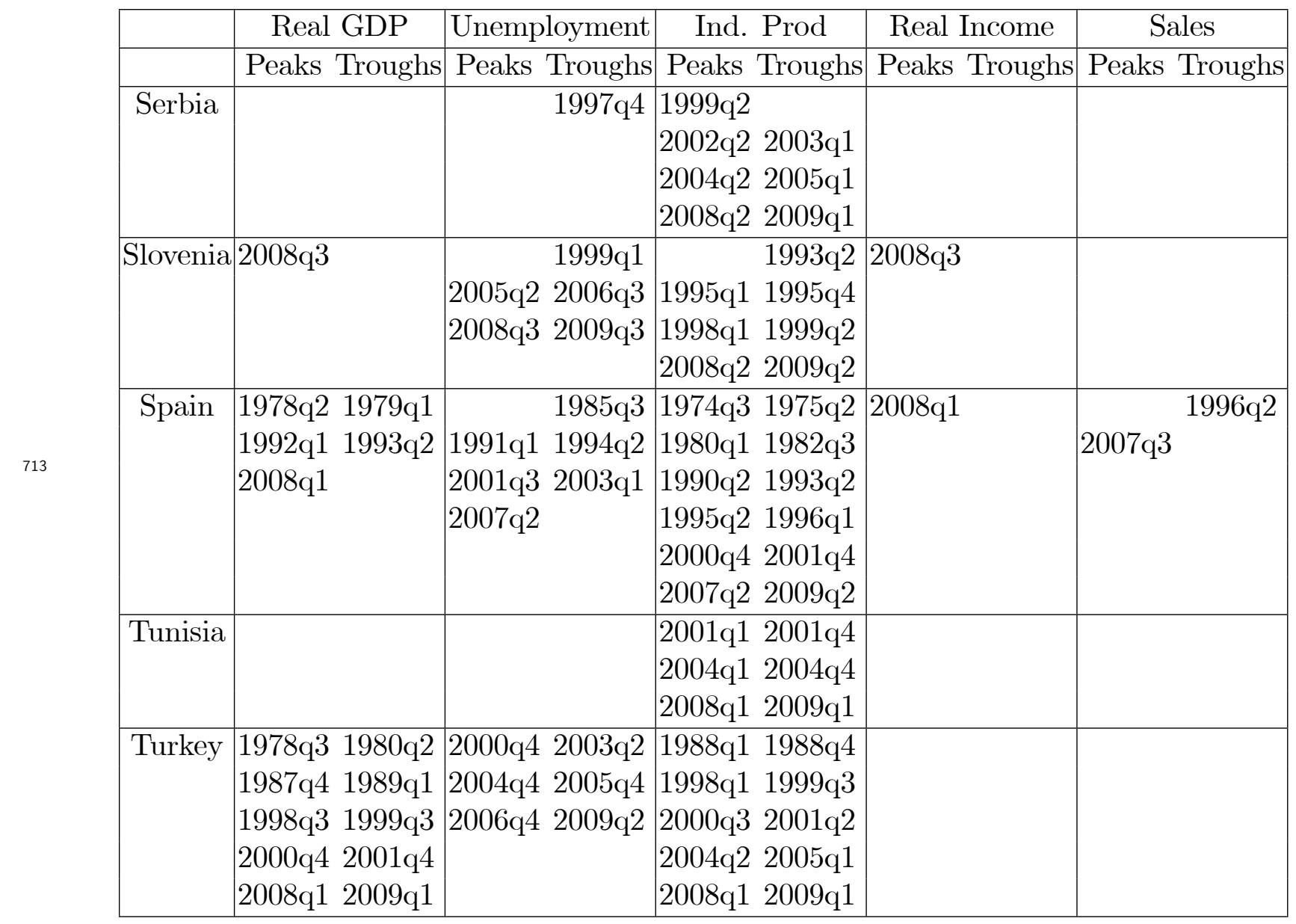

